\title{
Descriptive analysis of dental $X$-ray images using various practical methods: A review
}

\author{
Anuj Kumar ${ }^{\text {Corresp., }}{ }^{\text {, Harvendra Singh Bhadauria }}{ }^{1}$, Annapurna Singh ${ }^{1}$ \\ ${ }^{1}$ Department of Computer Science \& Engineering, Govind Ballabh Pant Institute of Engineering \& Technology, Ghurdauri, Pauri Garhwal, Uttarakhand, \\ India \\ Corresponding Author: Anuj Kumar \\ Email address: dranujdhiman@gmail.com
}

In dentistry, practitioners interpret various dental X-ray imaging modalities to identify tooth-related problems, abnormalities, or teeth structure changes. Another aspect of dental imaging is that it can be helpful in the field of biometrics. Human dental image analysis is a challenging and time-consuming process due to the unspecified and uneven structures of various teeth, and hence the manual investigation of dental abnormalities is at par excellence. However, automation in the domain of dental image segmentation and examination is essentially the need of the hour in order to ensure error-free diagnosis and better treatment planning. In this article, we have provided a comprehensive survey of dental image segmentation and analysis by investigating more than 130 research works conducted through various dental imaging modalities, such as various modes of X-ray, CT (Computed Tomography), CBCT (Cone Beam Computed Tomography), etc. Overall state-ofthe-art research works have been classified into three major categories, i.e., image processing, machine learning, and deep learning approaches, and their respective advantages and limitations are identified and discussed. The survey presents extensive details of the state-of-the-art methods, including image modalities, pre-processing applied for image enhancement, performance measures, and datasets utilized. 
1 Descriptive analysis of dental X-ray images using various practical methods: 2 A review

3 Anuj Kumar*a, Harvendra Singh Bhadauria ${ }^{a}$, Annapurna Singh ${ }^{a}$

4 dranujdhiman@gmail.com, hsb76iitr@gmail.com, annapurnasingh78@gmail.com

5 Department of Computer Science \& Engineering, Govind Ballabh Pant Institute of Engineering \&

6 Technology, Ghurdauri, Pauri Garhwal, Uttarakhand, India.

7 Abstract: In dentistry, practitioners interpret various dental X-ray imaging modalities to identify tooth8 related problems, abnormalities, or teeth structure changes. Another aspect of dental imaging is that it can 9 be helpful in the field of biometrics. Human dental image analysis is a challenging and time-consuming process due to the unspecified and uneven structures of various teeth, and hence the manual investigation of dental abnormalities is at par excellence. However, automation in the domain of dental image segmentation and examination is essentially the need of the hour in order to ensure error-free diagnosis and better treatment planning. In this article, we have provided a comprehensive survey of dental image segmentation and analysis by investigating more than 130 research works conducted through various dental imaging modalities, such as various modes of X-ray, CT (Computed Tomography), CBCT (Cone Beam Computed Tomography), etc. Overall state-of-the-art research works have been classified into three major categories, i.e., image processing, machine learning, and deep learning approaches, and their respective advantages and limitations are identified and discussed. The survey presents extensive details of the state-of-the-art methods, including image modalities, pre-processing applied for image enhancement, performance measures, and datasets utilized.

Keywords: Dental X-ray, Machine Learning, Deep Learning, Convolutional Neural Networks

\section{Introduction}

Dental X-ray imaging (DXRI) has been developed as the foundation for dental professionals across the world because of the assistance provided in detecting the abnormalities present in the teeth structures (Oprea et al., 2008). For dentists, radiography imparts a significant role in assisting imaging assessment in providing a thorough clinical diagnosis and dental structures preventive examinations (Molteni, 1993). However, to analyze a dental X-ray image, researchers primarily use image processing methods to extract the relevant information. Image segmentation is the most widely used image-processing technique to analyze medical images and help improve computer-aided medical diagnosis systems (Li et al., 2006; Shah et al., 2006).

Furthermore, Manual examination of a large collection of X-ray images can be time-consuming because visual inspection and tooth structure analysis have an abysmal sensitive rate; therefore, human screening may not identify a high proportion of caries (Olsen et al., 2009). In most cases, the automatic computerized tool that can help the investigation process would be highly beneficial (Abdi, Kasaei \& Mehdizadeh, 2015; Jain \& Chauhan, 2017). Dental image examination involved various stages consisting of image enhancement, segmentation, feature extractions, and identification of regions, which are subsequently valuable for detecting cavities, tooth fractures, cyst or tumor detection, root canal length, and growth tooth in children (Kutsch, 2011; Purnama et al., 2015). Also, various studies revealed that 
analysis of dental imaging modalities is beneficial in applications like human identification, age estimation, and biometrics (Nomir \& Abdel-Mottaleb, 2007; Caruso, Silvestri \& Sconfienza, 2013).

At present, Deep learning (DL) and Machine learning (ML) gained huge momentum in recent studies taking into consideration Fracture detection, Brain tumor localization, Cardiovascular diseases detection, skin cancer detection, plant diseases detection, Face recognition, Hand gesture classification, and medical image analysis (Goyal et al., 2019; Gadekallu et al., 2020, 2021; Joshi \& Singh, 2020; Rehman et al., 2020; Shabaan et al., 2020; Bhattacharya et al., 2021). Deep learning frameworks, well-known as convolutional neural networks (CNNs), are primarily employed for processing large and complex image datasets because they can obtain multiple features from obfuscated layers (Schmidhuber, 2015; Hwang et al., 2019). Many studies that used pre-trained networks like Alexnet, VGG, GoogLeNet, and Inception v3 found that they performed well in general. On the other hand, CNN networks tend to develop from shallow layer networks to broader or problem-specific self-made or complicated networks.

Recently, numerous machine learning approaches have been proposed by researchers to improve dental image segmentation and analysis performance. Deep learning and artificial intelligence techniques are remarkably successful in addressing the challenging segmentation dilemmas presented in various studies. (Hatvani et al., 2018; Lee et al., 2018a; Yang et al., 2018; Hwang et al., 2019; Sai Ambati et al., 2020; Khanagar et al., 2021), So we can foresee a whirlwind of inventiveness and lines of findings in the coming years, based on achievements that recommend machine learning models concerning semiotic segmentation for DXRI.

In the existing surveys (Rad et al., 2013; Schwendicke et al., 2019), various techniques and methods have been discussed for DXRI. In (Rad et al. 2013), Segmentation techniques are divided into three classes: pixel-based, edge-based, and region-based and further classified into thresholding, clustering boundarybased, region-based, or watershed approaches. However, there is no discussion on enhancement techniques, image databases used, and modalities used for DXRI. Furthermore, after (Rad et al., 2013) survey, a large number of approaches have been introduced by researchers. Next, a review of dental image diagnosis using convolution neural network is presented by (Schwendicke et al., 2019), focusing on diagnostic accuracy studies that pitted a $\mathrm{CNN}$ against a reference test, primarily on routine imagery data. It has been observed that in the previous surveys, a thorough investigation of traditional image processing, machine learning, and deep learning approaches is missing.

Being an emerging and promising research domain, dental X-ray imaging requires a comprehensive and detailed survey of dental image segmentation and analysis to diagnose and treat various dental diseases. In this study, we have made the following contributions that are missing in the previous surveys: Firstly, we have imparted various studies from 2004 to 2020 covering more than 130 articles and is almost double than previous surveys given by Rad et al. (2013) and Schwendicke et al. (2019). Secondly, we have presented X-ray pre-processing techniques, traditional image analysis approaches, machine learning, and deep learning advancements in DXRI. Third, specific image modality (such as periapical, panoramic, bitewing and CBCT, etc.) based methods are categorized. At last, performance metrics and dataset descriptions are investigated up to a great extent. Also, specific benchmarks in the advancement of DXRI methods are represented in Figure 1.

\subsection{A brief about dental imaging modalities}

Dental imaging modalities give insights into teeth growth, bone structures, soft tissues, tooth loss, decay and also helps in root canal treatment (RCT), which is not visible during a dentist's clinical inspection. 
81 Dental imaging modalities are mainly categorized as intra-oral and extra-oral X-rays. In dentistry, these images are frequently used for medical diagnosis (Abrahams, 2001; Caruso, Silvestri \& Sconfienza, 2013). Various Dental imaging modalities categorization based on intra-oral and extra-oral are presented in Figure 2.

Dental radiographs can discover problems in the mouth, jaws, teeth, bone loss, fractures, cysts at an early stage. X-rays can help in finding issues that can not be visualized with an oral assessment. Identifying and diagnosing problems at the earliest stage can save you from root canal treatment and other serious issues.

\section{Types of dental radiography}

Intra-oral radiography. An X-ray film is kept in the mouth to capture the X-ray picture, which comprises all the specific details about teeth arrangement, root canal infection, and identifying caries. Categories of intra-oral X-ray images are:

- Periapical images. It provides information of root and surrounding bone areas containing three to four teeth in the single X-ray image.

- Bitewing images. It generally helps in detecting the information of upper and lower tooth arrangements, and an X-ray beam shows the dentist how these teeth are arranged with one another and how to spot a cavity between teeth. Bitewing X-rays may also be used to ensure that a crown is fitted correctly (a tooth-enclosing cap) or tooth restoration is done accurately. It can also detect rotting or damaged fillings.

- Occlusal images. Occlusal X-rays provide insight into the mouth's base, revealing the upper or lower jaw's bite. They place a strong emphasis on children's tooth development and placement.

Extra-oral radiography. An X-ray picture is taken from outside the mouth to capture the entire skull and jaws region. Extra-oral X-rays are classified into many types.

- Panoramic X-rays. X-rays are full-sized and capture the overall tooth structure. Also, the pictures provide information about the skull and jaw. These images are mainly used to examine fractures, trauma, jaws diseases, pathological lesions and evaluate the impacted teeth.

- Cephalometric X-rays. Also called ceph X-ray, it depicts the jaw's whole part, including the head's entire side. It is employed in both dentistry and medicine for diagnosis and clinical preparation purposes.

- Sialogram. It uses a substance that is infused into the salivary glands to make them visible on X-ray film. Doctors may recommend this check to ensure problems with the salivary glands, such as infections or Sjogren's syndrome signs (a symptom condition identified by sore mouth and eyes; this condition may cause tooth decay).

- Computed tomography (CT). It is an imaging technique that gives insights into 3-D internal structures. This kind of visualization is used to identify maladies such as cysts, cancers, and fractures in the face's bones.

- Cone-beam computed tomography (CBCT) generates precise and high-quality pictures. Cone beam $\mathrm{CT}$ is an X-ray type that generates $3 \mathrm{D}$ visions of dental formations, soft tissues, nerves, and bones. It helps in guiding the tooth implants and finding cyst and tumefaction in the mouth. It can also find 
issues in the gum areas, roots, and jaws structures. Cone beam CT is identical to standard dental CT in several respects.

In this study, various articles considered in which the researchers proposed techniques that are extensively applied to periapical, bitewing, panoramic, CT, CBCT, and photographic color images. Digital X-ray imaging is currently gaining traction as a new research area with expanding applications in various fields.

\subsection{Challenges faced by doctors in analyzing dental $X$-ray images}

Dental practitioners used X-ray radiographs to examine dental anatomy and to determine the care strategy for the patient. Because of a lack of resources, X-ray interpretations rely more on the doctor's expertise, and manual examination is complex in dentistry (Wang et al., 2016). Therefore, computer-aided systems are introduced to reduce complexity and make the identification process easy and fast. Computer-aided systems are becoming more powerful and intelligent for identifying abnormalities after processing medical images (such as X-rays, Microscopic images, Ultrasound images, and MRI images). Healthcare decision support systems were developed to provide technical guidance to clinical decision-making experts in the healthcare field (Mendonça, 2004). These systems help identify and treat the earliest symptom of demineralization of tooth caries, root canal, and periodontal diseases.

This paper explores the potential computational methods used for developing computer-aided systems, identifies the challenges faced in their implementation, and provides future directions (Amer \& Aqel, 2015; Wang et al., 2016). Automatic detection of abnormalities, anomalies and abrupt changes in teeth structures is a big challenge for researchers. In this study, some of the tooth-related problems are imparted, which are still a challenge for researchers to develop expert systems. We have worked with some of the dental practitioners to understand the common problems. These problems are significantly related to cavities (or caries), root canal treatment (RCT), cysts, teeth implants, and teeth growth. Working in collaboration with dentists helps computer science professionals and researchers to design \& develop models that can solve dentist's problems during examination.

The dental X-ray image analysis methods can be categorized in several categories: region growing techniques, edge detection methods, thresholding based, clustering techniques, level set, and active contour, etc., are presented in Section 2.1 (Mahoor \& Abdel-Mottaleb, 2004; Zhou \& Abdel-Mottaleb, 2005; Nomir \& Abdel-Mottaleb, 2005, 2007; Gao \& Chae, 2008; Oprea et al., 2008; Patanachai, Covavisaruch \& Sinthanayothin, 2010; Harandi \& Pourghassem, 2011; Hu et al., 2014; Amer \& Aqel, 2015; Zak et al., 2017; Avuçlu \& Bacsçiftçi, 2020) (Rad et al., 2015; Tuan, Ngan \& others, 2016; Poonsri et al., 2016; Tuan \& others, 2016, 2017; Ali et al., 2018; Alsmadi, 2018; Obuchowicz Rafałand Nurzynska et al., 2018; Tuan et al., 2018; Fariza et al., 2019; Kumar, Bhadauria \& Singh, 2020).

Conventional machine learning methods considering: Back Propagation Neural Network (BPNN), Artificial Neural Network (ANN), Support vector machine (SVM), Random forest regression-voting constrained local model (RFRV-CLM), Hybrid learning algorithms are presented in Section 2.2 (Nassar \& Ammar, 2007; Fernandez \& Chang, 2012; Pushparaj et al., 2013; Prakash, Gowsika \& Sathiyapriya, 2015; Bo et al., 2017; Yilmaz, Kayikcioglu \& Kayipmaz, 2017; Vila-Blanco, Tomás \& Carreira, 2018). Also, considering Deep learning architectures, i.e., Conventional CNN and transfer learning, GoogLeNet Inception v3, AlexNet, Mask R-CNN model, ResNet-101, 6 - Layer DCNN, U-net architecture, and LightNet and MatConvNet, etc., are highlighted in Section 2.3 (Imangaliyev et al., 2016; Miki et al., 2017b,a; Oktay, 2017; Prajapati, Nagaraj \& Mitra, 2017; Rana et al., 2017; Srivastava et al., 2017; Chu et al., 2018; Lee et al., 2018a, 2019; Egger et al., 2018; Torosdagli et al., 2018; Yang et al., 2018; Zhang et 
161

162

163

164

165

166

167

168

169

170

171

172

173

174

175

176

177

178

179

180

181

182

183

184

185

186

187

188

189

190

191

192

193

194

195

196

197

198

199

al., 2018; Hatvani et al., 2018; Jader et al., 2018; Karimian et al., 2018; Kim et al., 2019; Murata et al., 2019; Tuzoff et al., 2019; Fukuda et al., 2019; Hiraiwa et al., 2019; Banar et al., 2020; Singh \& Sehgal, 2020; Geetha, Aprameya \& Hinduja, 2020).

\subsection{Contribution}

DXRI analysis is an evolving and prospective research field, but still, there is a lack of systematic study available except for one or two studies. In this study, we have made significant contributions as follows:

1. A comprehensive survey consisting of more than 130 articles related to dental imaging techniques for the last 15 years is presented.

2. Overall state-of-the-art research works have been classified into three major categories, i.e., image processing, machine learning, and deep learning approaches, and their respective advantages and limitations are identified and discussed

3. A comprehensive review of dental imaging methods provided in terms of various performance metrics

4. At last, a review of dental X-ray imaging datasets used for implementation and generation.

The rest of the review is structured as follows. The methodology is discussed in Section 2. Various performance metrics are presented in Section 3. DXRI datasets are given in Section 4. At last, the conclusion is given in Section 5.

\section{Methodology}

In this survey, 130 research articles from 2004 to 2020 have been reviewed, as shown in Figure 3, covering almost all research articles from different online digital libraries like Springer, Elsevier, IEEE, and Google Scholar. These articles are conferences, Book chapters, peer-reviewed and reputed journals in computer science and digital dental imaging. A total number of articles deliberating various imaging modalities: Periapical, Bitewing, Panoramic, Hybrid, CT or CBCT, Photographic color teeth images, and undefined datasets are given in Table 1. Methods are categorized as image processing techniques in Section 2.1, conventional machine learning methods are given in Section 2.2, and deep learning approaches are provided in Section 2.3. Also, methods are characterized based on imaging modalities (Periapical X-rays, Bitewing X-rays, Panoramic X-rays, CBCT or CT images, etc.), and DXRI methods taxonomy is given in Figure 4.

The research incorporated in this comprehensive review primarily focused on medical image processing and artificial intelligence for the detection and examination of the tooth cavity, periodontal disease recognition, tooth arrangement and numbering, root canal detection, periapical lesions detection, salivary gland disease diagnosis, cyst detection, osteoporosis detection, the progress of deciduous teeth, analysis of cephalometric landmarks and fracture identification, etc.

\subsection{Image processing methods for dental image analysis}

The research adopts various image processing strategies for dental imaging to investigate the structures of teeth, caries, and abnormalities to help dental practitioners for the appropriate diagnosis. It involves various pre-processing, segmentation, and classification approaches to make an automatic dental identification system that makes doctor's work more accessible, unambiguous, and faster. A simple traditional model used for dental image processing is given in Figure 5. 
200

201

202

203

204

205

206

207

208

209

210

211

212

213

214

215

216

217

218

219

220

221

222

223

224

225

226

227

228

229

230

231

232

233

234

235

236

237

238

239

240

241

242

\subsubsection{Pre-processing techniques}

Dental imaging consists of different image modalities, where X-rays are the most common medical imaging method used to classify bone and hard tissues. In dentistry, imaging modalities help identify fractures, teeth structures, jaws alignment, cyst, and bone loss, which has become tremendously popular in dental imaging (Goyal, Agrawal \& Sohi, 2018). Noise level, artifacts, and image contrast are vital values that control an image's overall quality. The image quality obtained depends on varying factors such as the dynamic range of the sensors, the lighting conditions, distortion, and the artifact examined (Sarage \& Jambhorkar, 2012). Interpretation of a low-resolution image is often a complex and time-consuming process. Pre-processing techniques enhance the quality of low-resolution images, which corrects the spatial resolution and local adjustment to improve the input image's overall quality (Hossain, Alsharif \& Yamashita, 2010). Moreover, enhancement and filtering methods improve the overall image quality parameters before further processing. In Table 2, pre-processing techniques are addressed to recuperate the quality of dental images.

Contrast stretching, Grayscale stretching, Log transformation, Gamma correction, image negative, and histogram equalization methods are standard enhancement methods to improve the quality of medical images. X-rays are typically grayscale pictures, with high noise rates and low resolution. Thus, the image contrast and boundary representation are relatively weak and small (Ramani, Vanitha \& Valarmathy, 2013). Extracting features from these X-rays is quite a difficult task with very minimal details and a lowquality image. By adding specific contrast enhancement techniques significantly improves image quality. So that segmentation and extraction of features from such images can be performed more accurately and conveniently (Kushol et al., 2019). Therefore, a contrast stretching approach has been widely used to enhance digital X-rays quality (Lai \& Lin, 2008; Vijayakumari et al., 2012; Berdouses et al., 2015; Purnama et al., 2015; Avuçlu \& Bacsçiftçi, 2020). Adaptive local contrast stretching makes use of local homogeneity to solve the problem of over and under enhancement. One of the prominent methods to refine the contrast of the image is Histogram Equalization (HE) (Harandi \& Pourghassem, 2011; Menon \& Rajeshwari, 2016; Obuchowicz Rafałand Nurzynska et al., 2018; Banday \& Mir, 2019). HE is the way of extending the dynamic range of an image histogram and it also causes unrealistic impacts in images; however, it is very effective for scientific pictures i.e satellite images, computed tomography, or X-rays. A downside of the approach is its indiscriminate existence. This can increase ambient noise contrast while reducing the useful quality features of an image.

On the other hand, filtering methods applied to medical images help to eradicate the noise up to some extent. Gaussian, Poisson, and quantum noise are different types of noise artifacts usually found in XRays \& CTs, particularly when the image is captured (Razifar et al., 2005; Goyal, Agrawal \& Sohi, 2018). The noise-free images achieve the efficiency to get the best result and improve the test's precision. If we try to minimize one class of noise, it may disrupt the other. Various filters have been used to achieve the best potential outcome for the irregularities present in dental images like Average filter, Bilateral filter, Laplacian filter, Homomorphic filter, and Butterworth filter, Median Gaussian filter, and Weiner filter. In recent studies, various filtering techniques used by researchers but widely used filtering methods are Gaussian filter and the median filter, which shows the best result (Benyó et al., 2009; Prajapati, Desai \& Modi, 2012; Nuansanong, Kiattisin \& Leelasantitham, 2014; Razali et al., 2014; Datta \& Chaki, 2015a,b; Rad et al., 2015; Tuan, Ngan \& others, 2016; Jain \& Chauhan, 2017; Alsmadi, 2018). However, the drawback of the median filter is that it degrades the boundary details. Whereas the Gaussian filter performs best in peak detection, the limitation is that it reduces the picture's information.

Peer) Comput. Sci. reviewing PDF | (CS-2021:03:59361:1:1:NEW 21 May 2021) 
243

244

245

246

247

248

249

250

251

252

253

254

255

256

257

258

259

260

261

262

263

264

265

266

267

268

269

270

271

272

273

274

275

276

277

278

279

280

281

282

283

284

\subsubsection{Dental image segmentation approaches used for different imaging modalities}

DXRI segmentation is an essential step to extract valuable information from various imaging modalities. In dentistry, segmentation faces more difficulties than other medical imaging modalities, making the segmentation process more complicated or challenging. Here, the problems faced by researchers in analyzing dental X-ray images and the purpose of segmentation are given in Figure 6. The segmentation process refers to the localization of artifacts or the boundary tracing, analysis of structure, etc. Human eyes distinguish the objects of interest quickly and remove them from the background tissues, but it is a great challenge in developing algorithms.

Furthermore, image segmentation has applications distinct from computer vision; it is often used to extract or exclude different portions of an image. General dental image segmentation methods are categorized as thresholding-based, contour or snake models, level set methods, clustering, and region growing (Rad et al., 2013). Moreover, there has been a significant number of surveys presented by various authors (Rad et al., 2013; Sharma, Rana \& Kundra, 2015). However, none of them categorized the methods based on dental imaging modalities. Various segmentation and classification techniques are discussed and reviewed in this article, considering multiple dental imaging modalities. In the field of dental imaging, the choice of selecting a correct algorithm for the particular image dataset is most important. This study explores image processing techniques explicitly applied for dental imaging modalities, as given in Table 3.

Bitewing X-rays are widely used by researchers for the application of human identification and biometrics. Human identification is achieved by applying adaptive thresholding, iterative thresholding, and region growing approaches. Afterwards, image features are extracted to archive and retrieve dental images used for human identification (Mahoor \& Abdel-Mottaleb, 2004, 2005; Nomir \& Abdel-Mottaleb, 2005, 2007, 2008; Zhou \& Abdel-Mottaleb, 2005). In (Huang et al., 2012), missing tooth locations were detected with an adaptive windowing scheme combined with the isolation curve method, which shows the accuracy rate higher than (Nomir \& Abdel-Mottaleb, 2005). In (Pushparaj, Gurunathan \& Arumugam, 2013), primarily aimed at estimating the shape of the entire tooth. In which segmentation is performed by applying horizontal and vertical integral projection. In addition, teeth boundary was estimated using the fast connected component labeling algorithm, and lastly, Mahalanobis distance is measured for the matching.

Periapical $X$-rays help in clinical diagnosis considering dental caries and root canal regions by applying various image processing techniques (Oprea et al., 2008). Many times dentists use periapical X-ray images to spot caries lesions from dental X-rays. Regardless of human brain vision, it is often hard to correctly identify caries by manually examining the X-ray image. Caries detection methods for periapical $\mathrm{X}$-rays have been used iteratively to isolate the initially suspected areas. Then, separated regions are subsequently analyzed. In (Rad et al., 2015), automatic caries identified by applying segmentation using k-means clustering and feature detection using GLCM. However, it shows image quality issues in some cases, and because of these issues, tooth detection may give a false result. On the other hand, (Singh \& Agarwal, 2018) applied color masking techniques to mark the curios lesions to find the percentage value of the affected area.

Another approach is given by (Osterloh \& Viriri, 2019) mainly focused on upper and lower jaws separation with the help of thresholding and integral projection, and the learning model is employed to extract caries. This model shows better accuracy than (Dykstra, 2008; Tracy et al., 2011; Valizadeh et al.,

Peer) Comput. Sci. reviewing PDF | (CS-2021:03:59361:1:1:NEW 21 May 2021) 
2015). In (Obuchowicz Rafałand Nurzynska et al., 2018), k-means clustering (CLU) and first-order features (FOF) were used to show the best performance for the identification of caries. However, this approach applied to the dataset of 10 patients with confirmed caries. A geodesic contour technique (Datta, Chaki \& Modak, 2019) shows better computational time results than multilevel thresholding, watershed, and level set. The limitation of this approach is that it does not work well for poor-quality pictures, which leads to inappropriate feature extraction. In (Datta, Chaki \& Modak, 2020), a method reduced the computational efforts and caries region identified in optimum time. The X-ray image is processed in the neutrosophic domain to identify the suspicious part, and an active contour method is employed to detect the outer line of the carious part. The benefit of this method is that it prevents recursive iterations using neutrosophication during suspicious area detection.

The semi-automatic method for root canal length detection is proposed by (Harandi \& Pourghassem, 2011; Purnama et al., 2015) to help dental practitioners properly treat root canal treatment (RCT). In some studies, periapical X-rays are also used for the automatic segmentation of cyst or abscess. (Devi, Banumathi \& Ulaganathan, 2019) proposed a fully automated hybrid method that combined featurebase isophote curvature and model-based fast marching (FMM). It shows good accuracy and optimum results as compared to (Jain \& Chauhan, 2017). Furthermore, various approaches were used to automatically detect teeth structures (Huang \& Hsu, 2008; Sattar \& Karray, 2012; Niroshika, Meegama \& Fernando, 2013; Nuansanong, Kiattisin \& Leelasantitham, 2014; Kumar, Bhadauria \& Singh, 2020).

Panoramic X-rays help identify jaw fractures, the structure of jaws, and deciduous teeth. These X-rays are less detailed as compared to periapical and bitewing. It has been observed that the segmentation of panoramic X-rays using wavelet transformation shows better results than adaptive and iterative thresholding (Patanachai, Covavisaruch \& Sinthanayothin, 2010). Another, fully automatic segmentation of the teeth using the template matching technique introduced by (Poonsri et al., 2016) shows 50\% matching accuracy results. In (Razali et al., 2014) analyzed X-rays for the age estimations by comparing edge detection approaches. (Amer \& Aqel, 2015) have suggested a method used to extract wisdom teeth using the Otsu's threshold combined with morphological dilation. Then, jaws and teeth regions are extracted using connected component labeling.

In (Mahdi \& Kobashi, 2018), it sets a multi-threshold by applying quantum particle swarm optimization to improve the accuracy. (Fariza et al., 2019) employed a method to extract dentin, enamel, pulp, and other surrounding dental structures using conditional spatial fuzzy C-means clustering. Subsequently, the performance improved as compared to inherently used FCM approaches. (Dibeh, Hilal \& Charara, 2018) separates maxillary and mandibular jaws using N-degree polynomial regression. In (Abdi, Kasaei \& Mehdizadeh, 2015), a four-step method is proposed: gap valley extraction, modified canny edge detector, guided iterative contour tracing, and template matching. However, estimating the overall performance of automated segmentation with individual results, all of which were estimated to be above $98 \%$, clearly demonstrates that the computerized process can still be improved to meet the gold standard more precisely.

In (Veena Divya, Jatti \& Revan Joshi, 2016), active contour-based segmentation is proposed for cystic lesion segmentation and extraction to analyze cyst development behavior. The segmentation method has positive results for nonlinear background, poor contrast, and noisy image. The author (Divya et al., 2019) has compared the level set method and watershed segmentation to detect cyst and lesion. The study reveals that the level set segmentation produces more predicted results for cyst/Lesion. An approach used 
327

328

329

330

331

332

333

334

335

336

337

338

339

340

341

342

343

344

345

346

347

348

349

350

351

352

353

354

355

356

357

358

359

360

361

362

363

364

365

366

367

368

to identify age \& gender by analyzing dental images is very useful in biometrics (Avuçlu \& Bacsçiftçi, 2020). Several other image processing techniques are used on dental images to achieve the best biometric results.

Hybrid-dataset is the image dataset combining different dental imaging modalities used for the analysis. (Said et al., 2006) have used periapical \& bitewing X-rays for the teeth segmentation. In this approach, the background area is discarded using an appropriate threshold, then mathematical morphology and connected component labeling are applied for the teeth extraction. This approach finds difficulty in extracting images having low contrast between teeth and bones, blurred images, etc. Another approach introduced by (Tuan, Ngan \& others, 2016; Tuan \& others, 2017; Tuan et al., 2018) the semi-supervised fuzzy clustering method with some modification to find the various teeth and bone structures. (Ali, Ejbali \& Zaied, 2015) compared CPU \& GPU results after applying the Chan-Vese model with active contour without edge. It shows that GPU model implementation is several times faster than the CPU version.

Photographic color images are the RGB images of occlusal surfaces that are mainly useful for detecting caries and human identification (Datta \& Chaki, 2015a,b). Teeth segmentation is performed by integrating watershed and snake-based techniques on dental RGB images. Subsequently, incisors tooth features extracted for the recognition of a person. This method can segment individual teeth, lesions from caries and track the development of lesion size. This research's primary objective is to identify the caries lesions of the tooth surfaces, which benefits to improve the diagnosis. In (Ghaedi et al., 2014), caries segmentation was employed using the region-widening method and circular hough transform (CHT), then morphological operations applied to locate the unstable regions around the tooth boundaries. Another fully automatic approach for the caries classification is given by (Berdouses et al., 2015), where segmentation separates caries lesion then after area features are extracted to assign the region to a particular class. It can be a valuable method to support the dentist in making more reliable and accurate detection and analysis of occlusal caries.

$\boldsymbol{C T} \& \boldsymbol{C B C T}$ Images provide 3D visualization of teeth and assist dental practitioners in orthodontic surgery, dental implants, and cosmetic surgeries. The study (Hosntalab et al., 2010) recommended a multi-step procedure for labeling and classification in CT images. However, teeth segmentation is performed by employing global thresholding, morphological operations, region growing, and variational level sets. Another approach, a multi-step procedure, was introduced by (Mortaheb, Rezaeian \& Soltanian-Zadeh, 2013) based on the mean shift algorithm for CT image segmentation of the tooth area, which results best as compare with watershed, thresholding, active contour. Another technique that does not depend on mean shift is suggested by (Gao \& Li, 2013), which uses an iterative scheme to label events for the segmentation. Furthermore, segmentation methods are improved by applying active contour tracking algorithms and level set methods (Gao \& Chae, 2010). It shows higher accuracy and visualization of tooth regions as compared to other methods.

\subsection{Conventional machine learning algorithms for dental image analysis}

Development in the field of Machine Learning (ML) and Artificial Intelligence (AI) is growing over the last few years. ML and AI methods have made a meaningful contribution to the field of dental imaging, such as computer-aided diagnosis \& treatment, X-ray image interpretation, image-guided treatment, infected area detection, and information representation adequately and efficiently. The ML and AI make it easier and help doctors diagnose and presume disease risk accurately and more quickly in time. Conventional machine learning algorithms for image perception rely exclusively on expertly designed

Peer) Comput. Sci. reviewing PDF | (CS-2021:03:59361:1:1:NEW 21 May 2021) 
features, i.e., identifying dental caries involves extracting texture features - an overview of various machine learning algorithms given in Figure 7.

ML datasets are generally composed of exclusive training, validation, and test sets. It determines system characteristics by evaluating and testing the dataset then validates the features acquired from the input data. Using the test dataset, one might finally verify ML's precision and extract valuable features to formulate a powerful training model. Table 4 reveals the conventional machine-learning algorithms used for dental X-ray imaging.

\subsection{Deep learning techniques for dental image analysis}

Artificial intelligence, machine learning, and deep learning approaches assist medical imaging technicians in spotting abnormalities and diagnosing disorders in a fraction of the time required earlier (and with more accurate tests generally). Deep learning (DL) is an improvement of artificial neural networks $(\mathrm{ANN})$, which has more layers and allows for more accurate data predictions (LeCun, Bengio \& Hinton, 2015; Schmidhuber, 2015). Deep learning is associated with developing self-learning back-propagation techniques that incrementally optimize data outcomes and increase computing power. Deep learning is a rapidly developing field with numerous applications in the healthcare sector. The number of available, high-quality datasets in ML and DL applications plays a significant role in evaluating the outcome accuracy. Also, information fusion assists in integrating multiple datasets and their use of DL models to enhance accuracy parameters. The predictive performance of deep learning algorithms in the medical imaging field exceeds human skill levels, transforming the role of computer-assisted diagnosis into a more interactive one (Burt et al., 2018; Park \& Park, 2018).

Health diagnostic computer-aided software is used in the medical field as a secondary tool, but developing traditional CAD systems tend to be very strenuous. Recently, there have been introducing deep learning approaches to $\mathrm{CAD}$, with accurate outcomes for different clinical applications (Cheng et al., 2016). The research study mostly used a convolution neural network model to analyze other dental imaging modalities. CNN's are a typical form of deep neural network feed-forward architectures, and they are usually used for computer vision and image object identification tasks. CNN's were initially released about two decades back; however, in 2012, AlexNet 's architecture outpaced added ImageNet large-scale competition challenges (Krizhevsky, Sutskever \& Hinton, 2012). Machine vision came in as the deep learning revolution, and since then, CNNs have been rapidly evolving. Feature learning methods have taken a massive turn since the CNN model has come into the picture. Fully convolution neural network Alexnet architecture is used to categorize teeth, including molar, premolar, canine, and incisor, by training cone-beam CT images (Miki et al., 2017a; Oktay, 2017). (Tuzoff et al., 2019) applied the Faster R-CNN model, which interprets pipeline and optimizes computation to detect the tooth (Ren et al., 2017) and VGG-16 convolutional architecture for classification (Simonyan \& Zisserman, 2014). These methods are beneficial in practical applications and further investigation of computerized dental X-ray image analysis.

In DXRI, CNNs have been extensively used to detect tooth fractures, bone loss, caries detection, periapical lesions, or also used for the analysis of different dental structures (Lee et al., 2018b; Schwendicke et al., 2019). Neural networks need to be equipped and refined, and X-ray dataset repositories are necessary (Lee et al., 2018a). In (Lee et al., 2019), the mask R-CNN model is applied based on a CNN that can identify, classify, and mask artifacts in an image. A mask R-CNN mask operated in two steps. In the first step, the Region of interest (ROIs) selection procedure was performed. 
411 Next, the R-CNN mask includes a binary mask similarity to the classification and bounding box foresight 412 for each ROI (Romera-Paredes \& Torr, 2016; He et al., 2017).

413 Dental structures (enamel, dentin, and pulp) identified using U-net architecture show the best outcome 414 (Ronneberger, Fischer \& Brox, 2015). CNN is a standard technique for multi-class identification and 415 characterization, but it requires extensive training to achieve a successful result if used explicitly. In the 416 medical sphere, the lack of public data is a general problem because of privacy. To address this issue, 417 (Zhang et al., 2018) suggested a technique that uses a label tree to assign multiple labels to each tooth and 418 decompose a task that can manage data shortages. Table 5 presents various studies considering deep 419 learning-based techniques in the field of dentistry.

\subsection{Challenges and future directions}

421

422

423

424

425

426

427

428

429

430

431

432

433

434

435

436

437

438

439

440

441

442

443

444

445

446

447

448

449

450

After reviewing various works focusing on traditional image processing techniques, it has been perceived that researchers faced multiple challenges in the field of DXRI segmentation and analysis, such as intensity variation in the X-ray images, poor image quality due to noise, irregular shape of an object, limitations of capturing devices, proper selection of methodology and lack of availability of datasets. Also, experience severe challenges in automatically detecting abnormalities, root canal infection, and sudden changes in the oral cavity. Since there are different varieties of dental X-ray images, it is hard to find a particular segmentation approach; it all depends on the precise condition of the X-rays. Some articles have used pre-processed digital X-rays that were manually cropped to include the area of interest. Because of inconsistencies in the manual method, it is hard to accurately interpret and compare outcomes (Lee, Park \& Kim, 2017).

Moreover, convolutional neural networks (and their derivatives) are performing outstandingly in dental $\mathrm{X}$-ray image analysis. One notable conclusion is that many researchers use almost the same architectures, the same kind of network, but have very different outcomes. Deep neural networks are most successful when dealing with a large training dataset, but large datasets are not publically available in the DXRI and are not annotated. If vast publicly accessible dental X-ray image datasets were constructed, our research community would undoubtedly benefit exceedingly.

For the future perspective, the dental X-ray image public repository needs to be developed, and data uniformity is required for deep learning applications in dentistry. Also, DXRI aims to create a classifier that can classify multiple anomalies, caries classes, types of jaw lesions, Cyst, Root canal infection, etc., in dental images using features derived from the segmentation results. There is also a need to build machine learning-based investigative methods and rigorously validate them with a large number of dental professionals. The participation of specialists in this process will increase the likelihood of growth and development. Currently, there exists no universally acceptable software or tool for dental image analysis. However, such a tool is essentially needed to improve the performance of CAD systems and better treatment planning.

\section{Performance measures}

In general, if the algorithm's efficiency is more significant than other algorithms, one algorithm is prioritized over another. Evaluating the effectiveness of a methodology requires the use of a universally accessible and valid measure. Various performance metrics have been used to compare algorithms or machine learning approaches depending on the domain or study area. It comprises accuracy, Jaccard 
451

452

453

454

455

456

457

458

459

460

461

462

463

464

465

466

467

468

469

470

471

472

473

474

475

476

477

478

479

480

481

482

483

484

485

486

487

488

489

index, sensitivity, precision, recall, DSC, F-measure, AUC, MSE, Error rate, etc. Here, we include a thorough analysis of the success metrics employed in dental image analysis.

\subsection{Performance metrics used for dental image processing}

Calculating performance metrics used for dental segmentation is performed by authenticating pixel by pixel and analyzing the segmentation results with the gold standard. Manual annotation of X-ray images done by a radiologist is considered to be the gold standard. Pixel-based metrics are measured using precision, dice coefficient, accuracy, specificity, and F-score widely used in segmentation analysis. Some of the problems in analyzing image segmentation are metric selection, the use of multiple meanings for some metrics in the literature, and inefficient metric measurement implementations that lead to significant large volume dataset difficulties. Poorly described metrics can result in imprecision conclusions on stateof-the-art algorithms, which affects the system's overall growth. Table 6 presents an overview of performance metrics widely used by researchers for dental image segmentation and analysis.

The significance of accuracy and assurance is essential in the medical imaging field. Also, the validation of segmentation achieves the result and dramatically increases the precision, accuracy, conviction, and computational speed of segmentation. Segmentation methods are especially helpful in computer-aided medical diagnostic applications where the interpretation of objects that are hard to differentiate by human vision is a significant component.

\subsection{Confusion Matrix}

The confusion matrix is used to estimate the performance of medical image segmentation and classification. The confusion matrix helps identify the relationship between the outcomes of the predictive algorithm and the actual ones. Some of the terms used for the confusion matrix are given in Table 7, True positive (TP): Correctly identified or detected, False positive (FP): Evaluated or observed incorrectly, False negative (FN): wrongly rejected, True Negative (TN): Correctly rejected. In the approach (Mahoor \& Abdel-Mottaleb, 2005), experimental outcomes proved that molar classification is relatively easy compared to premolars, and for teeth classification, centroid distance is less effective than a coordinate signature. Various metrics such as the Signature vector, Force field (FF), and Fourier descriptor (FD) were used to test the efficiency of the approach given by (Nomir \& Abdel-Mottaleb, 2007), and for matching euclidean distance and absolute distance, FF \& FD give small values, suggesting that they performed better than the others. Here, FF \& FD give small values for matching Euclidean distance and absolute distance, indicating that the performance is better than the other two methods. In another approach (Prajapati, Desai \& Modi, 2012), feature vectors are evaluated and used to find the image distance vector $\left(D_{n}\right)$ using formula: $D_{n}=\sum\left|T_{n} F V-F V Q\right|$, where feature vector $(T n F V)$ is used for database image and (FVQ) is used for the query image. The minimum value of the distance vector indicates the best match of the image with the database image.

The study (Huang et al., 2012) shows better isolation precision accuracy for the segmentation of jaws as compared with Nomir and Abdel-Mottaleb. Another method evaluated the complete length of the tooth and capered with the dentist's manual estimation (Harandi \& Pourghassem, 2011). Here, measurement

Peer) Comput. Sci. reviewing PDF | (CS-2021:03:59361:1:1:NEW 21 May 2021) 
490 error (ME) is evaluated for root canals applying the formula: $M E=\frac{\text { Mesured length }}{\text { Actual length }}$ and evaluated ME is 491 lowest for one canal compared to two and three canals.

492 (Niroshika, Meegama \& Fernando, 2013) traced the tooth boundaries using active contour and distance 493 parameters are compared with the Kass algorithm. The value of the standard distance parameter was 494 found to be lower than that of the Kass algorithm, implying that the proposed method is more efficient for

495

496

497

498

499

500

501

502

503

504

505

506

507

508

509

510

511

512

513

514

515

516

517

518

519

520

521

522

523

524

525

526

527

528

529

530

531 tracing the tooth boundary than the Kass algorithm. Another approach used for counting molar and premolar teeth is considering precision and sensitivity (Pushparaj et al., 2013). Here performance is using metric ' $\eta$ ' is given by: $\eta=\frac{(m-n)}{n} * 100$. Where ' $m$ ' represents the total number of teeth counted, and ' $n$ ' represents the incorrectly numbered teeth. The counting of molar and premolar teeth is more than $90 \%$ accurate using this method.

In (Abdi, Kasaei \& Mehdizadeh, 2015), mandible segmentation and Hausdorff distance parameters were compared to the manually annotated gold standard. The algorithm results appear to be very close to the manually segmented gold standard in terms of sensitivity, accuracy, and dice similarity coefficient (DSC). In this study (Amer \& Aqel, 2015), a wisdom tooth is extracted, and the mean absolute error (MAE) is used to equate the procedure with the other two methods. As compared to other approaches, the lower MAE value showed better segmentation.

In (Poonsri et al., 2016), precision is calculated for single-rooted and double-rooted teeth using template matching. According to their study, segmentation accuracy is greater than $40 \%$. (Tuan \& others, 2016, 2017) used the following cluster validity metrics: PBM, Simplified Silhouette Width Criterion (SSWC), Davis-Bouldin (DB), BH, VCR, BR, and TRA, and the measures of these parameters indicate the best performance as compared with the results of current algorithms.

PBM: The maximum value of this index is said to be the PBM index, across the hierarchy provides the best partitioning.

Simplified Silhouette Width Criterion (SSWC): The silhouette analysis tests how well the observation is clustered and calculates the average distance between clusters. The silhouette plot shows how similar each point in a cluster is to the neighboring clusters' points.

Davies-Bouldin index $(D B)$ : This index determines the average 'similarity' amongst clusters, in which the resemblance is a metric that measures the distance between clusters with the size of clusters themselves. The lower Davies-Bouldin index refers to a model with a greater detachment of clusters.

Ball and Hall index (BH): It is used to determine the distance within a group, with a higher value showing better results.

Calinski-Harabasz index, also called Variance Ratio Criterion (VCR): It can be applied to evaluate the partition data by variance, and its higher value indicates good results.

Banfeld-Raftery index (BR): It is evaluated using a variance-covariance matrix for each cluster.

Difference-like index (TRA): It calculates the cluster difference, and a higher value gives the best results.

Comparison of various performance metrics used in dental X-ray imaging considering deep learning methods are given in Figure 8.

\section{Dataset Description}

The researcher in the dental imaging field has used various types of databases. In which some of the databases are available online, while some records are not present. The most prominent dilemma is finding out which investigation has given valid results because everyone has shown promising results on their datasets. All the dental imaging databases that have been used so far are given in Table 8. 
532

533

534

535

536

537

538

539

540

541

542

543

544

545

546

547

548

549

550

551

552

553

554

555

556

557

558

559

560

561

562

563

564

565

566

567

568

569

570

571

\section{Conclusion}

Dental X-ray image analysis is a challenging area, and it receives significantly less attention from the community of researchers. There is, however, no systematic review that addresses the state-of-the-art approaches of DXRI. This paper has performed a thorough analysis of more than 130 techniques suggested by different researchers over the last few decades. This study presented a survey of various segmentation and classification techniques widely used for dental X-ray imaging. Methods are characterized as image processing, conventional machine learning, and deep learning. Furthermore, a novel taxonomy mainly focusing on the imaging modalities-based categorization such as bitewing, periapical, panoramic, CBCT/CT, hybrid datasets, and color pictures. Various studies have found that opting for one type of segmentation technique is very difficult in conventional image-processing methods because of image dataset variability. The primary barrier in the growth of a high-performance classification model is the requirement of an annotated datasets, as pointed by various researchers mentioned in this study. Dental Imaging data is not the same as other medical images because of the different image characteristics. This difference has an impact on the deep learning model's adaptability during image classification. It is also challenging to validate and verify the algorithm's correctness because of the inadequate datasets available for the hypothesis.

Now we would like to bring the researcher's attention towards future directions in DXRI. Since most dental X-ray image analysis methods result in decreased efficiency, more sophisticated segmentation techniques should be designed to improve clinical treatment. Further, It is being observed that limited work is employed in the recent studies to detect caries classes such as class I, class II, class III, class IV, class V, class VI, and root canal infection. Researchers should therefore focus on implementing new methodologies for caries classification and detection. Recently, deep learning has improved DXRI segmentation and classification performance and requires large annotated image datasets for training, but large annotated X-ray datasets are not publicly accessible. Further, a public repository for dental X-ray images needs to be developed. It is still an open problem so that we can expect new findings and research outcomes in the coming years.

\section{References}

Abdi AH, Kasaei S, Mehdizadeh M. 2015. Automatic segmentation of mandible in panoramic x-ray. Journal of Medical Imaging 2:44003.

Abrahams JJ. 2001. Dental CT Imaging: A Look at the Jaw. Radiology 219:334-345. DOI: 10.1148/radiology.219.2.r01ma33334.

Ali R Ben, Ejbali R, Zaied M. 2015. GPU-based segmentation of dental x-ray images using active contours without edges. In: 2015 15th International Conference on Intelligent Systems Design and Applications (ISDA). 505-510.

Ali M, Khan M, Tung NT, others. 2018. Segmentation of dental X-ray images in medical imaging using neutrosophic orthogonal matrices. Expert Systems with Applications 91:434-441.

Alsmadi MK. 2018. A hybrid Fuzzy C-Means and Neutrosophic for jaw lesions segmentation. Ain Shams Engineering Journal 9:697-706.

Amer YY, Aqel MJ. 2015. An efficient segmentation algorithm for panoramic dental images. Procedia Computer Science 65:718-725. 
572

573

574

575

576

577

578

579

580

581

582

583

584

585

586

587

588

589

590

591

592

593

594

595

596

597

598

599

600

601

602

603

604

605

606

607

608

609

610

611
Avuçlu E, Bacsçiftçi F. 2020. The determination of age and gender by implementing new image processing methods and measurements to dental X-ray images. Measurement 149:106985.

Banar N, Bertels J, Laurent F, Boedi RM, De Tobel J, Thevissen P, Vandermeulen D. 2020. Towards fully automated third molar development staging in panoramic radiographs. International Journal of Legal Medicine:1-11.

Banday M, Mir AH. 2019. Dental Biometric Identification System using AR Model. In: TENCON 20192019 IEEE Region 10 Conference (TENCON). 2363-2369.

Benyó B, Szilágyi L, Haidegger T, Kovács L, Nagy-Dobó C. 2009. Detection of the root canal's centerline from dental micro-CT records. In: 2009 Annual International Conference of the IEEE Engineering in Medicine and Biology Society. 3517-3520.

Berdouses ED, Koutsouri GD, Tripoliti EE, Matsopoulos GK, Oulis CJ, Fotiadis DI. 2015. A computeraided automated methodology for the detection and classification of occlusal caries from photographic color images. Computers in biology and medicine 62:119-135.

Bhattacharya S, Maddikunta PKR, Pham Q-V, Gadekallu TR, Chowdhary CL, Alazab M, Piran MJ, others. 2021. Deep learning and medical image processing for coronavirus (COVID-19) pandemic: A survey. Sustainable cities and society 65:102589.

Black G V. 1981. Extracts from the last century. Susceptibility and immunity by dental caries by G.V. Black. British dental journal 151:10. DOI: 10.1038/sj.bdj.4804617.

Bo C, Liang X, Chu P, Xu J, Wang D, Yang J, Megalooikonomou V, Ling H. 2017. Osteoporosis prescreening using dental panoramic radiographs feature analysis. In: 2017 IEEE 14th International Symposium on Biomedical Imaging (ISBI 2017). 188-191.

Burt JR, Torosdagli N, Khosravan N, RaviPrakash H, Mortazi A, Tissavirasingham F, Hussein S, Bagci U. 2018. Deep learning beyond cats and dogs: recent advances in diagnosing breast cancer with deep neural networks. The British journal of radiology 91:20170545.

Caruso P, Silvestri E, Sconfienza LM. 2013. Cone Beam CT and 3D imaging. Springer Science \& Business Media. DOI: 10.1007/978-88-470-5319-9.

Cheng J-Z, Ni D, Chou Y-H, Qin J, Tiu C-M, Chang Y-C, Huang C-S, Shen D, Chen C-M. 2016. Computer-aided diagnosis with deep learning architecture: applications to breast lesions in US images and pulmonary nodules in CT scans. Scientific reports 6:1-13.

Chu P, Bo C, Liang X, Yang J, Megalooikonomou V, Yang F, Huang B, Li X, Ling H. 2018. Using octuplet siamese network for osteoporosis analysis on dental panoramic radiographs. In: 2018 40th Annual International Conference of the IEEE Engineering in Medicine and Biology Society (EMBC). 2579-2582.

Datta S, Chaki N. 2015a. Person identification technique using RGB based dental images. In: IFIP International Conference on Computer Information Systems and Industrial Management. 169-180.

Datta S, Chaki N. 2015b. Detection of dental caries lesion at early stage based on image analysis technique. In: 2015 IEEE International Conference on Computer Graphics, Vision and Information Security (CGVIS). 89-93.

Datta S, Chaki N, Modak B. 2019. A Novel Technique to Detect Caries Lesion Using Isophote Concepts. IRBM 40:174-182.

Peer] Comput. Sci. reviewing PDF | (CS-2021:03:59361:1:1:NEW 21 May 2021) 
612 Datta S, Chaki N, Modak B. 2020. Neutrosophic Set-Based Caries Lesion Detection Method to Avoid

$613 \quad$ Perception Error. SN Computer Science 1:63.

614 Devi RK, Banumathi A, Ulaganathan G. 2019. An automated and hybrid method for cyst segmentation in 615 dental X-ray images. Cluster Computing 22:12179-12191.

616 Dibeh G, Hilal A, Charara J. 2018. A Novel Approach for Dental Panoramic Radiograph Segmentation. In: 2018 IEEE International Multidisciplinary Conference on Engineering Technology (IMCET). 16.

Dykstra B. 2008. Interproximal caries detection: how good are we? Dentistry today 27:144-146.

623

624

625

626

627

628

629

630

631

632

633

634

635

636

637

638

639

640

641

642

643

644

645

646

647

648

649

650
Egger J, Pfarrkirchner B, Gsaxner C, Lindner L, Schmalstieg D, Wallner J. 2018. Fully convolutional mandible segmentation on a valid ground-truth dataset. In: 2018 40th Annual International Conference of the IEEE Engineering in Medicine and Biology Society (EMBC). 656-660.

Fariza A, Arifin AZ, Astuti ER, Kurita T. 2019. Segmenting tooth components in dental X-ray images using Gaussian kernel- based conditional spatial Fuzzy C-Means clustering algorithm. International Journal of Intelligent Engineering and Systems 12. DOI: 10.22266/IJIES2019.0630.12.

Fernandez K, Chang C. 2012. Teeth/palate and interdental segmentation using artificial neural networks. In: IAPR Workshop on Artificial Neural Networks in Pattern Recognition. 175-185.

Fukuda M, Inamoto K, Shibata N, Ariji Y, Yanashita Y, Kutsuna S, Nakata K, Katsumata A, Fujita H, Ariji E. 2019. Evaluation of an artificial intelligence system for detecting vertical root fracture on panoramic radiography. Oral Radiology:1-7.

Gadekallu TR, Alazab M, Kaluri R, Maddikunta PKR, Bhattacharya S, Lakshmanna K, Parimala M. 2021. Hand gesture classification using a novel CNN-crow search algorithm. Complex $\mid \&$ Intelligent Systems:1-14.

Gadekallu TR, Rajput DS, Reddy MPK, Lakshmanna K, Bhattacharya S, Singh S, Jolfaei A, Alazab M. 2020. A novel PCA--whale optimization-based deep neural network model for classification of tomato plant diseases using GPU. Journal of Real-Time Image Processing:1-14.

Gao H, Chae O. 2008. Automatic tooth region separation for dental CT images. In: 2008 Third International Conference on Convergence and Hybrid Information Technology. 897-901.

Gao H, Chae O. 2010. Individual tooth segmentation from CT images using level set method with shape and intensity prior. Pattern Recognition 43:2406-2417.

Gao Y, Li X. 2013. Teeth segmentation via semi-supervised learning. In: 2013 6th International Conference on Biomedical Engineering and Informatics. 558-563.

Geetha V, Aprameya KS, Hinduja DM. 2020. Dental caries diagnosis in digital radiographs using backpropagation neural network. Health Information Science and Systems 8:1-14.

Ghaedi L, Gottlieb R, Sarrett DC, Ismail A, Belle A, Najarian K, Hargraves RH. 2014. An automated dental caries detection and scoring system for optical images of tooth occlusal surface. In: 2014 36th Annual International Conference of the IEEE Engineering in Medicine and Biology Society. 1925-

Peer] Comput. Sci. reviewing PDF | (CS-2021:03:59361:1:1:NEW 21 May 2021) 
651

652

653

654

655

656

657

658

659

660

661

662

663

664

665

666

667

668

669

670

671

672

673

674

675

676

677

678

679

680

681

682

683

684

685

686

687

688

689

1928.

Goyal B, Agrawal S, Sohi BS. 2018. Noise Issues Prevailing in Various Types of Medical Images. Biomedical \& Pharmacology Journal 11:1227.

Goyal V, Singh G, Tiwari O, Punia S, Kumar M, others. 2019. Intelligent skin cancer detection mobile application using convolution neural network. Journal of Advanced Research in Dynamical and Control Systems (JARCDS) 11:253-259.

Harandi AA, Pourghassem H. 2011. A semi automatic algorithm based on morphology features for measuring of root canal length. In: 2011 IEEE 3rd International Conference on Communication Software and Networks. 260-264.

Hatvani J, Horváth A, Michetti J, Basarab A, Kouamé D, Gyöngy M. 2018. Deep learning-based superresolution applied to dental computed tomography. IEEE Transactions on Radiation and Plasma Medical Sciences 3:120-128.

He K, Gkioxari G, Dollár P, Girshick R. 2017. Mask r-cnn. In: Proceedings of the IEEE international conference on computer vision. 2961-2969.

Hiraiwa T, Ariji Y, Fukuda M, Kise Y, Nakata K, Katsumata A, Fujita H, Ariji E. 2019. A deep-learning artificial intelligence system for assessment of root morphology of the mandibular first molar on panoramic radiography. Dentomaxillofacial Radiology 48:20180218.

Hosntalab M, Zoroofi RA, Tehrani-Fard AA, Shirani G. 2010. Classification and numbering of teeth in multi-slice CT images using wavelet-Fourier descriptor. International journal of computer assisted radiology and surgery 5:237-249.

Hossain MF, Alsharif MR, Yamashita K. 2010. Medical image enhancement based on nonlinear technique and logarithmic transform coefficient histogram matching. In: IEEE/ICME International Conference on Complex Medical Engineering. 58-62.

Hu Z, Wu PZ, Gui J, Chen Y, Zheng H. 2014. Teeth segmentation using dental CT data. In: 2014 7th International Conference on Biomedical Engineering and Informatics. 81-84.

Huang C-H, Hsu C-Y. 2008. Computer-assisted orientation of dental periapical radiographs to the occlusal plane. Oral Surgery, Oral Medicine, Oral Pathology, Oral Radiology, and Endodontology 105:649-653.

Huang P-W, Lin P-L, Kuo C-H, Cho YS. 2012. An effective tooth isolation method for bitewing dental X-ray images. In: 2012 International Conference on Machine Learning and Cybernetics. 18141820.

Hwang J-J, Jung Y-H, Cho B-H, Heo M-S. 2019. An overview of deep learning in the field of dentistry. Imaging science in dentistry 49:1.

Iannucci J, Howerton LJ. 2012. Dental Radiography, 5th Edition. Elsevier saunders.

Imangaliyev S, van der Veen MH, Volgenant CMC, Keijser BJF, Crielaard W, Levin E. 2016. Deep learning for classification of dental plaque images. In: International Workshop on Machine Learning, Optimization, and Big Data. 407-410.

Jader G, Fontineli J, Ruiz M, Abdalla K, Pithon M, Oliveira L. 2018. Deep instance segmentation of teeth in panoramic X-ray images. In: 2018 31st SIBGRAPI Conference on Graphics, Patterns and Images 
690

691

692

693

694

695

696

697

698

699

700

701

702

703

704

705

706

707

708

709

710

711

712

713

714

715

716

717

718

719

720

721

722

723

724

725

726

727

(SIBGRAPI). 400-407.

Jain KR, Chauhan NC. 2017. An Automatic Segmentation Approach Towards the Objectification of Cyst Diagnosis in Periapical Dental Radiograph. In: International Conference on Information and Communication Technology for Intelligent Systems. 164-172.

Joshi D, Singh TP. 2020. A survey of fracture detection techniques in bone X-ray images. Artificial Intelligence Review 53:4475-4517.

Karimian N, Salehi HS, Mahdian M, Alnajjar H, Tadinada A. 2018. Deep learning classifier with optical coherence tomography images for early dental caries detection. In: Lasers in Dentistry XXIV. 1047304.

Khanagar SB, Al-ehaideb A, Maganur PC, Vishwanathaiah S, Patil S, Baeshen HA, Sarode SC, Bhandi S. 2021. Developments, application, and performance of artificial intelligence in dentistry - A systematic review. Journal of Dental Sciences 16:508-522. DOI: 10.1016/j.jds.2020.06.019.

Kim J, Lee H-S, Song I-S, Jung K-H. 2019. DeNTNet: Deep Neural Transfer Network for the detection of periodontal bone loss using panoramic dental radiographs. Scientific reports 9:1-9.

Krizhevsky A, Sutskever I, Hinton GE. 2012. Imagenet classification with deep convolutional neural networks. In: Advances in neural information processing systems. 1097-1105.

Kumar A, Bhadauria HS, Singh A. 2020. Semi-supervised OTSU based hyperbolic tangent Gaussian kernel fuzzy C-mean clustering for dental radiographs segmentation. Multimedia Tools and Applications 79:2745-2768.

Kushol R, Raihan M, Salekin MS, Rahman ABM, others. 2019. Contrast Enhancement of Medical X-Ray Image Using Morphological Operators with Optimal Structuring Element. arXiv preprint arXiv:1905.08545.

Kutsch VK. 2011. Caries Detection, Inside Dentistry. AEGIS Communications.

Lai YH, Lin PL. 2008. Effective segmentation for dental X-ray images using texture-based fuzzy inference system. In: International Conference on Advanced Concepts for Intelligent Vision Systems. 936-947.

LeCun Y, Bengio Y, Hinton G. 2015. Deep learning. nature 521.

Lee J-H, Han S-S, Kim YH, Lee C, Kim I. 2019. Application of a fully deep convolutional neural network to the automation of tooth segmentation on panoramic radiographs. Oral Surgery, Oral Medicine, Oral Pathology and Oral Radiology.

Lee J-H, Kim D-H, Jeong S-N, Choi S-H. 2018a. Detection and diagnosis of dental caries using a deep learning-based convolutional neural network algorithm. Journal of dentistry 77:106-111.

Lee J-H, Kim D, Jeong S-N, Choi S-H. 2018b. Diagnosis and prediction of periodontally compromised teeth using a deep learning-based convolutional neural network algorithm. Journal of periodontal \& implant science 48:114-123.

Lee H, Park M, Kim J. 2017. Cephalometric landmark detection in dental x-ray images using convolutional neural networks. In: Medical Imaging 2017: Computer-Aided Diagnosis. 101341W.

Li S, Fevens T, Krzyżak A, Li S. 2006. Automatic clinical image segmentation using pathological

Peer] Comput. Sci. reviewing PDF | (CS-2021:03:59361:1:1:NEW 21 May 2021) 
modeling, PCA and SVM. Engineering Applications of Artificial Intelligence 19:403-410.

729

730

731

732

733

734

735

736

737

738

739

740

741

742

743

744

745

746

747

748

749

750

751

752

753

754

755

756

757

758

759

760

761

762

763

764

765

Mahdi FP, Kobashi S. 2018. Quantum Particle Swarm Optimization for Multilevel Thresholding-Based Image Segmentation on Dental X-Ray Images. In: 2018 Joint 10th International Conference on Soft Computing and Intelligent Systems (SCIS) and 19th International Symposium on Advanced Intelligent Systems (ISIS). 1148-1153.

Mahoor MH, Abdel-Mottaleb M. 2004. Automatic classification of teeth in bitewing dental images. In: 2004 International Conference on Image Processing, 2004. ICIP'04. 3475-3478.

Mahoor MH, Abdel-Mottaleb M. 2005. Classification and numbering of teeth in dental bitewing images. Pattern Recognition 38:577-586. DOI: 10.1016/j.patcog.2004.08.012.

Mendonça EA. 2004. Clinical decision support systems: perspectives in dentistry. Journal of dental education 68:589-597.

Menon HP, Rajeshwari B. 2016. Enhancement of dental digital X-ray images based on the image quality. In: The International Symposium on Intelligent Systems Technologies and Applications. 33-45.

Miki Y, Muramatsu C, Hayashi T, Zhou X, Hara T, Katsumata A, Fujita H. 2017a. Classification of teeth in cone-beam CT using deep convolutional neural network. Computers in biology and medicine 80:24-29.

Miki Y, Muramatsu C, Hayashi T, Zhou X, Hara T, Katsumata A, Fujita H. 2017b. Tooth labeling in cone-beam CT using deep convolutional neural network for forensic identification. In: Medical Imaging 2017: Computer-Aided Diagnosis. 101343E.

Molteni R. 1993. Direct digital dental x-ray imaging with Visualix/VIXA. Oral surgery, oral medicine, oral pathology 76:235-243.

Mortaheb P, Rezaeian M, Soltanian-Zadeh H. 2013. Automatic dental CT image segmentation using mean shift algorithm. In: 2013 8th Iranian Conference on Machine Vision and Image Processing (MVIP). 121-126.

Murata M, Ariji Y, Ohashi Y, Kawai T, Fukuda M, Funakoshi T, Kise Y, Nozawa M, Katsumata A, Fujita H, others. 2019. Deep-learning classification using convolutional neural network for evaluation of maxillary sinusitis on panoramic radiography. Oral radiology 35:301-307.

Nassar DEM, Ammar HH. 2007. A neural network system for matching dental radiographs. Pattern Recognition 40:65-79.

Niroshika UAA, Meegama RGN, Fernando TGI. 2013. Active contour model to extract boundaries of teeth in dental X-ray images. In: 2013 8th International Conference on Computer Science \& Education. 396-401.

Nomir O, Abdel-Mottaleb M. 2005. A system for human identification from X-ray dental radiographs. Pattern Recognition 38:1295-1305.

Nomir O, Abdel-Mottaleb M. 2007. Human identification from dental X-ray images based on the shape and appearance of the teeth. IEEE transactions on information forensics and security 2:188-197.

Nomir O, Abdel-Mottaleb M. 2008. Fusion of matching algorithms for human identification using dental $\mathrm{X}$-ray radiographs. IEEE Transactions on Information Forensics and Security 3:223-233.

Peer) Comput. Sci. reviewing PDF | (CS-2021:03:59361:1:1:NEW 21 May 2021) 
766

767

768

769

770

771

772

773

774

775

776

777

778

779

780

781

782

783

784

785

786

787

788

789

790

791

792

793

794

795

796

797

798

799

800

801

802

803

804

Nuansanong J, Kiattisin S, Leelasantitham A. 2014. Diagnosis and interpretation of dental X-ray in case of deciduous tooth extraction decision in children using active contour model and J48 tree. In: 2014 International Electrical Engineering Congress (iEECON). 1-4.

Obuchowicz Rafałand Nurzynska K, Obuchowicz B, Urbanik A, Piórkowski A. 2018. Caries detection enhancement using texture feature maps of intraoral radiographs.

Oktay AB. 2017. Tooth detection with Convolutional Neural Networks. In: 2017 Medical Technologies National Congress (TIPTEKNO). 1-4.

Olsen GF, Brilliant SS, Primeaux D, Najarian K. 2009. An image-processing enabled dental caries detection system. In: 2009 ICME International Conference on Complex Medical Engineering. 1-8.

Oprea S, Marinescu C, Lita I, Jurianu M, Visan DA, Cioc IB. 2008. Image processing techniques used for dental x-ray image analysis. In: 2008 31st international spring seminar on electronics technology. $125-129$.

Osterloh D, Viriri S. 2019. Caries Detection in Non-standardized Periapical Dental X-Rays. In: Computer Aided Intervention and Diagnostics in Clinical and Medical Images. Springer, 143-152.

Park WJ, Park J-B. 2018. History and application of artificial neural networks in dentistry. European journal of dentistry 12:594-601.

Patanachai N, Covavisaruch N, Sinthanayothin C. 2010. Wavelet transformation for dental X-ray radiographs segmentation technique. In: 2010 Eighth International Conference on ICT and Knowledge Engineering. 103-106.

Poonsri A, Aimjirakul N, Charoenpong T, Sukjamsri C. 2016. Teeth segmentation from dental x-ray image by template matching. In: 2016 9th Biomedical Engineering International Conference (BMEiCON). 1-4.

Prajapati DB, Desai NP, Modi CK. 2012. A simple and novel CBIR technique for features extraction using AM dental radiographs. In: 2012 International Conference on Communication Systems and Network Technologies. 198-202.

Prajapati SA, Nagaraj R, Mitra S. 2017. Classification of dental diseases using CNN and transfer learning. In: 2017 5th International Symposium on Computational and Business Intelligence (ISCBI). 70-74.

Prakash M, Gowsika U, Sathiyapriya S. 2015. An identification of abnormalities in dental with support vector machine using image processing. In: Emerging Research in Computing, Information, Communication and Applications. Springer, 29-40.

Purnama IKE, Kurniastuti I, Rinastiti M, Purnomo MH. 2015. Semi-automatic determination of root canal length in dental X-ray image. In: 2015 4th International Conference on Instrumentation, Communications, Information Technology, and Biomedical Engineering (ICICI-BME). 49-53.

Pushparaj V, Gurunathan U, Arumugam B. 2013. An effective dental shape extraction algorithm using contour information and matching by mahalanobis distance. Journal of digital imaging 26:259-268.

Pushparaj V, Gurunathan U, Arumugam B, Baskaran A, Valliappan A. 2013. An effective numbering and classification system for dental panoramic radiographs. In: 2013 Fourth International Conference on Computing, Communications and Networking Technologies (ICCCNT). 1-8.

Peer] Comput. Sci. reviewing PDF | (CS-2021:03:59361:1:1:NEW 21 May 2021) 
805

806

807

808

809

810

811

812

813

814

815

816

817

818

819

820

821

822

823

824

825

826

827

828

829

830

831

832

833

834

835

836

837

838

839

840

841

842

843

Rad AE, Amin IBM, Rahim MSM, Kolivand H. 2015. Computer-aided dental caries detection system from X-ray images. In: Computational Intelligence in Information Systems. Springer, 233-243.

Rad AE, Mohd Rahim MS, Rehman A, Altameem A, Saba T. 2013. Evaluation of current dental radiographs segmentation approaches in computer-aided applications. IETE Technical Review $30: 210-222$.

Ramani R, Vanitha NS, Valarmathy S. 2013. The pre-processing techniques for breast cancer detection in mammography images. International Journal of Image, Graphics and Signal Processing 5:47.

Rana A, Yauney G, Wong LC, Gupta O, Muftu A, Shah P. 2017. Automated segmentation of gingival diseases from oral images. In: 2017 IEEE Healthcare Innovations and Point of Care Technologies (HI-POCT). 144-147.

Razali MRM, Ahmad NS, Hassan R, Zaki ZM, Ismail W. 2014. Sobel and canny edges segmentations for the dental age assessment. In: 2014 International Conference on Computer Assisted System in Health. 62-66.

Razifar P, Sandström M, Schnieder H, Långström B, Maripuu E, Bengtsson E, Bergström M. 2005. Noise correlation in PET, CT, SPECT and PET/CT data evaluated using autocorrelation function: a phantom study on data, reconstructed using FBP and OSEM. BMC medical imaging 5:5.

Rehman ZU, Zia MS, Bojja GR, Yaqub M, Jinchao F, Arshid K. 2020. Texture based localization of a brain tumor from MR-images by using a machine learning approach. Medical hypotheses 141:109705.

Ren S, He K, Girshick R, Sun J. 2017. Faster r-cnn: Towards real-time object detection with region proposal networks In IEEE Transactions on Pattern Analysis and Machine Intelligence (pp. 1137-1149). Los Alamitos, CA: IEEE 10.

Romera-Paredes B, Torr PHS. 2016. Recurrent instance segmentation. In: European conference on computer vision. 312-329.

Ronneberger O, Fischer P, Brox T. 2015. U-net: Convolutional networks for biomedical image segmentation. In: International Conference on Medical image computing and computer-assisted intervention. 234-241.

Sai Ambati L, Narukonda K, Bojja GR, Bishop D. 2020. Factors Influencing the Adoption of Artificial Intelligence in Organizations-From an Employee's Perspective.

Said E, Fahmy GF, Nassar D, Ammar H. 2004. Dental x-ray image segmentation. In: Biometric Technology for Human Identification. 409-417.

Said EH, Nassar DEM, Fahmy G, Ammar HH. 2006. Teeth segmentation in digitized dental X-ray films using mathematical morphology. IEEE transactions on information forensics and security 1:178189.

Sarage GN, Jambhorkar S. 2012. Enhancement of chest X-ray images using filtering techniques. Int J Adv Res Comput Sci Softw Eng 2:308-312.

Sattar F, Karray FO. 2012. Dental x-ray image segmentation and object detection based on phase congruency. In: International Conference Image Analysis and Recognition. 172-179.

Schmidhuber J. 2015. Deep learning in neural networks: An overview. Neural networks 61:85-117.

Peer) Comput. Sci. reviewing PDF | (CS-2021:03:59361:1:1:NEW 21 May 2021) 
844

845

846

847

848

849

850

851

852

853

854

855

856

857

858

859

860

861

862

863

864

865

866

867

868

869

870

871

872

873

874

875

876

877

878

879

880

881

Schwendicke F, Golla T, Dreher M, Krois J. 2019. Convolutional neural networks for dental image diagnostics: A scoping review. Journal of dentistry:103226.

Shabaan M, Arshad K, Yaqub M, Jinchao F, Zia MS, Boja GR, Iftikhar M, Ghani U, Ambati LS, Munir R. 2020. Survey: smartphone-based assessment of cardiovascular diseases using ECG and PPG analysis. BMC medical informatics and decision making 20:1-16.

Shah S, Abaza A, Ross A, Ammar H. 2006. Automatic tooth segmentation using active contour without edges. In: 2006 Biometrics Symposium: Special Session on Research at the Biometric Consortium Conference. 1-6.

Sharma M, Rana NK, Kundra H. 2015. A Review on the Existing Image Segmentation Techniques for the Dental X-Ray Images. 3:15-19.

Simonyan K, Zisserman A. 2014. Very deep convolutional networks for large-scale image recognition. arXiv preprint arXiv:1409.1556.

Singh HV, Agarwal R. 2018. Diagnosis of Carious Legions Using Digital Processing of Dental Radiographs. In: Computational Vision and Bio Inspired Computing. Springer, 864-882.

Singh P, Sehgal P. 2020. Numbering and Classification of Panoramic Dental Images Using 6-Layer Convolutional Neural Network. Pattern Recognition and Image Analysis 30:125-133.

Srivastava MM, Kumar P, Pradhan L, Varadarajan S. 2017. Detection of tooth caries in bitewing radiographs using deep learning. arXiv preprint arXiv:1711.07312.

Torosdagli N, Liberton DK, Verma P, Sincan M, Lee JS, Bagci U. 2018. Deep geodesic learning for segmentation and anatomical landmarking. IEEE transactions on medical imaging 38:919-931.

Tracy KD, Dykstra BA, Gakenheimer DC, Scheetz JP, Lacina S, Scarfe WC, Farman AG. 2011. Utility and effectiveness of computer-aided diagnosis of dental caries. Gen Dent 59:136-144.

Tuan TM, Fujita H, Dey N, Ashour AS, Ngoc VTN, Chu D-T, others. 2018. Dental diagnosis from X-ray images: an expert system based on fuzzy computing. Biomedical Signal Processing and Control 39:64-73.

Tuan TM, Ngan TT, others. 2016. A novel semi-supervised fuzzy clustering method based on interactive fuzzy satisficing for dental X-ray image segmentation. Applied Intelligence 45:402-428.

Tuan TM, others. 2016. A cooperative semi-supervised fuzzy clustering framework for dental X-ray image segmentation. Expert Systems with Applications 46:380-393.

Tuan TM, others. 2017. Dental segmentation from X-ray images using semi-supervised fuzzy clustering with spatial constraints. Engineering Applications of Artificial Intelligence 59:186-195.

Tuzoff D V, Tuzova LN, Bornstein MM, Krasnov AS, Kharchenko MA, Nikolenko SI, Sveshnikov MM, Bednenko GB. 2019. Tooth detection and numbering in panoramic radiographs using convolutional neural networks. Dentomaxillofacial Radiology 48:20180051.

Valizadeh S, Goodini M, Ehsani S, Mohseni H, Azimi F, Bakhshandeh H. 2015. Designing of a computer software for detection of approximal caries in posterior teeth. Iranian Journal of Radiology 12.

Veena Divya K, Jatti A, Revan Joshi P. 2016. Appending active contour model on digital panoramic dental X-rays images for segmentation of maxillofacial region. In: 2016 IEEE EMBS Conference on

Peer] Comput. Sci. reviewing PDF | (CS-2021:03:59361:1:1:NEW 21 May 2021) 
882

883

884

885

886

887

888

889

890

891

892

893

894

895

896

897

898

899

900

901

902

903

904

905

906

907

908

909

Biomedical Engineering and Sciences (IECBES), Kaula Lumpur, Malaysia. 4-8.

Vijayakumari B, Ulaganathan G, Banumathi A, Banu AFS, Kayalvizhi M. 2012. Dental cyst diagnosis using texture analysis. In: 2012 International Conference on Machine Vision and Image Processing (MVIP). 117-120.

Vila-Blanco N, Tomás I, Carreira MJ. 2018. Fully Automatic Teeth Segmentation in Adult OPG Images. Multidisciplinary Digital Publishing Institute Proceedings 2:1199.

Wang C-W, Huang C-T, Lee J-H, Li C-H, Chang S-W, Siao M-J, Lai T-M, Ibragimov B, Vrtovec T, Ronneberger O, others. 2016. A benchmark for comparison of dental radiography analysis algorithms. Medical image analysis 31:63-76.

Wirtz A, Mirashi SG, Wesarg S. 2018. Automatic teeth segmentation in panoramic X-ray images using a coupled shape model in combination with a neural network. In: International Conference on Medical Image Computing and Computer-Assisted Intervention. 712-719.

Wolff MS, Allen K, Kaim J. 2007. A 100-year journey from GV Black to minimal surgical intervention. Compendium of continuing education in dentistry (Jamesburg, NJ: 1995) 28:130-4.

Yang J, Xie Y, Liu L, Xia B, Cao Z, Guo C. 2018. Automated dental image analysis by deep learning on small dataset. In: 2018 IEEE 42nd Annual Computer Software and Applications Conference (COMPSAC). 492-497.

Yilmaz E, Kayikcioglu T, Kayipmaz S. 2017. Computer-aided diagnosis of periapical cyst and keratocystic odontogenic tumor on cone beam computed tomography. Computer methods and programs in biomedicine 146:91-100.

Zak J, Korzynska A, Roszkowiak L, Siemion K, Walerzak S, Walerzak M, Walerzak K. 2017. The method of teeth region detection in panoramic dental radiographs. In: International Conference on Computer Recognition Systems. 298-307.

Zhang K, Wu J, Chen H, Lyu P. 2018. An effective teeth recognition method using label tree with cascade network structure. Computerized Medical Imaging and Graphics 68:61-70.

Zhou J, Abdel-Mottaleb M. 2005. A content-based system for human identification based on bitewing dental X-ray images. Pattern Recognition 38:2132-2142. 
Figure 1

\section{Selected benchmarks for different years for dental imaging methods}

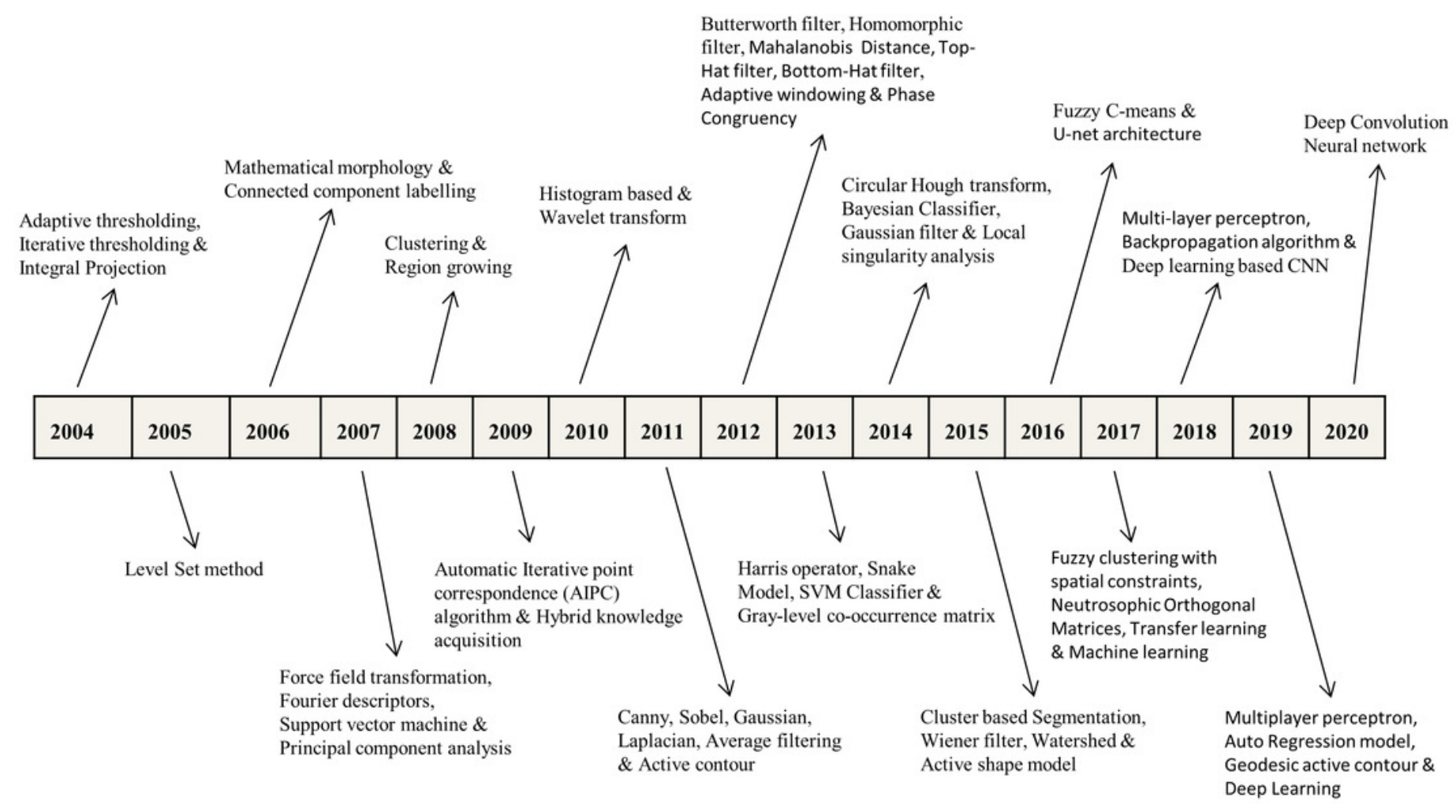


Figure 2

Overview of dental imaging modalities

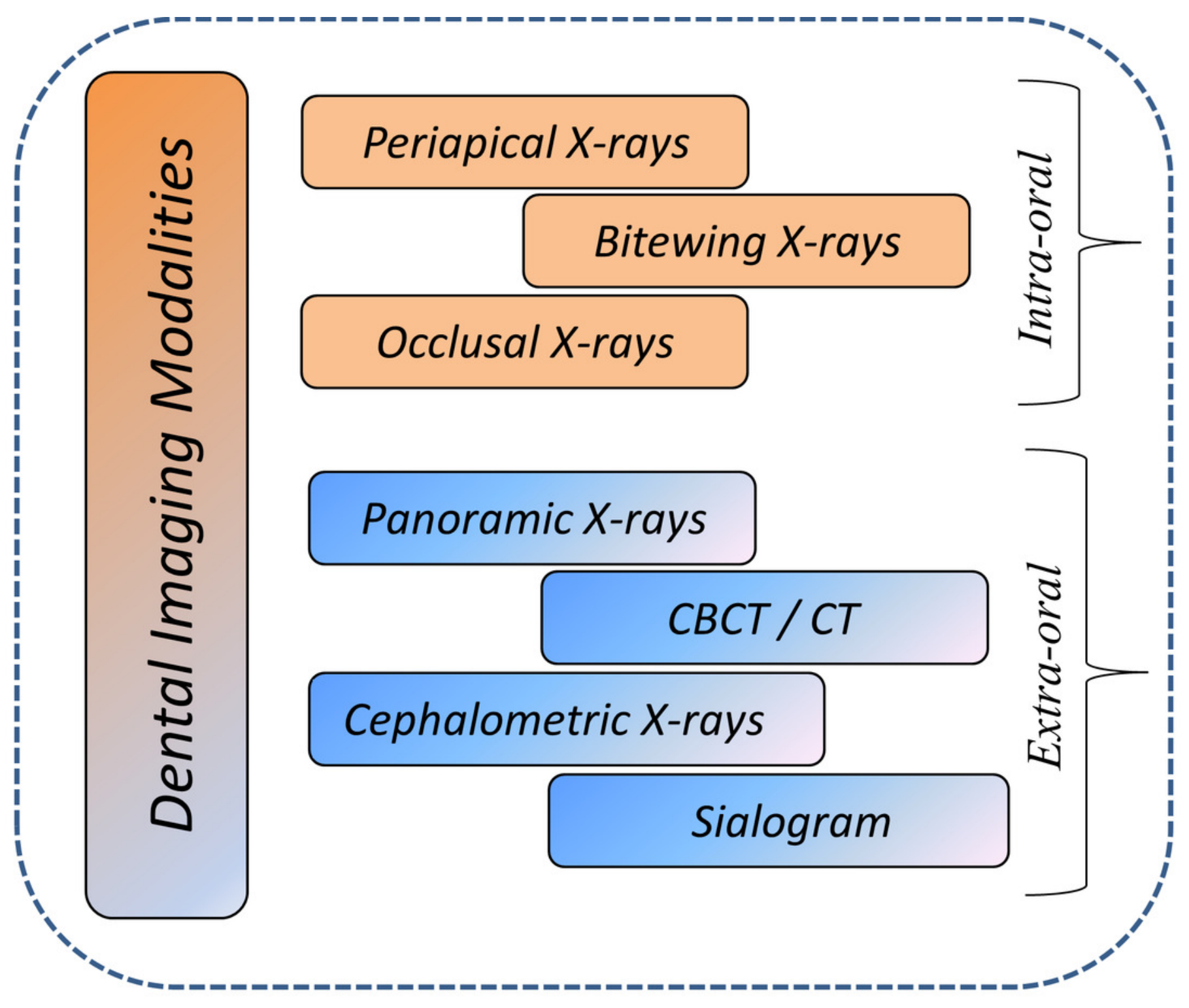


Figure 3

Number of research articles as per publication years in DXRI

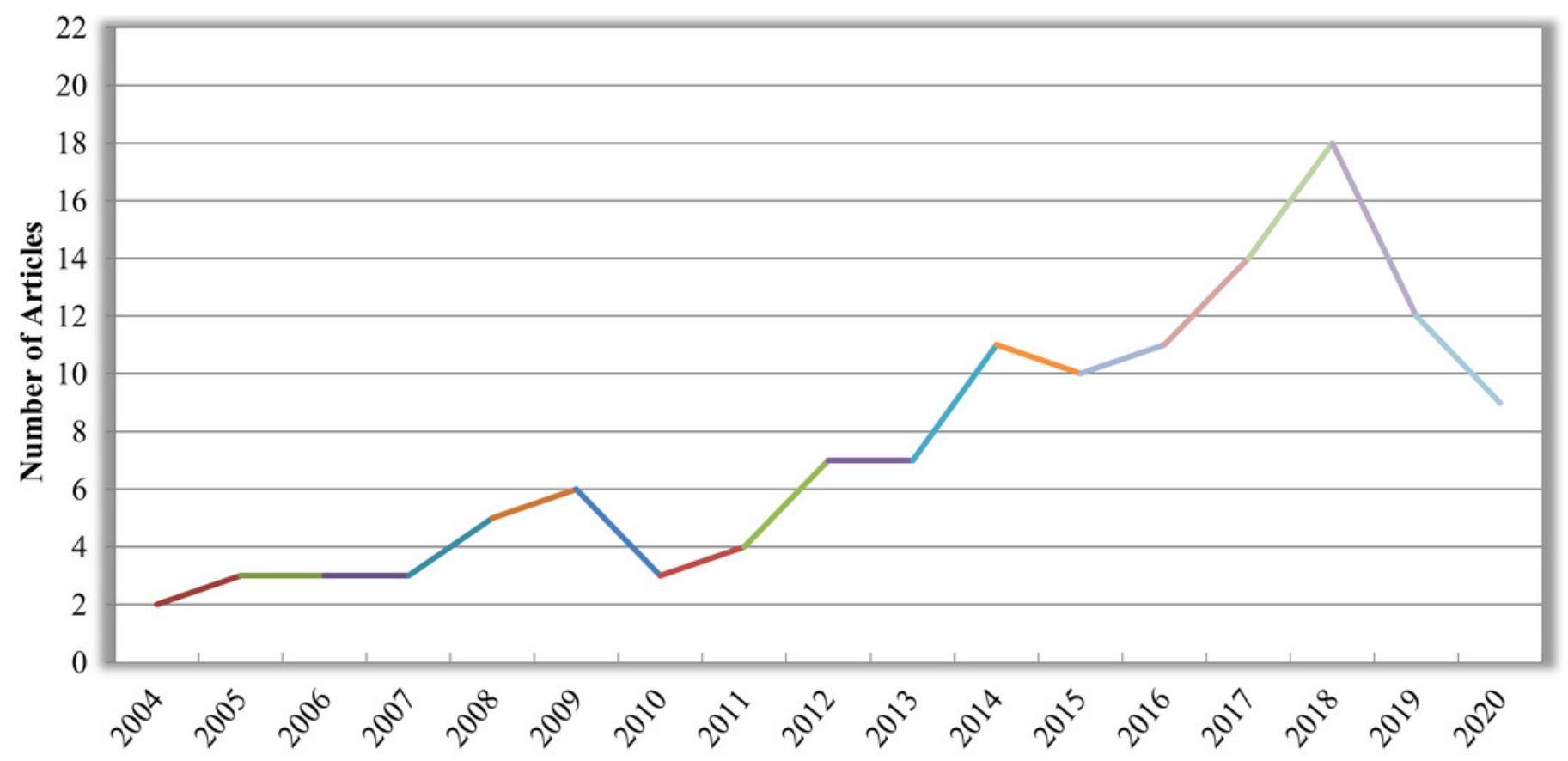

Publication Years 
Figure 4

Proposed taxonomy of DXRI methods

\begin{tabular}{|c|c|c|c|}
\hline 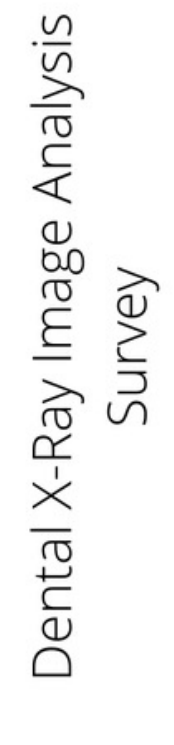 & $\begin{array}{c}\text { Traditional image } \\
\text { processing methods } \\
\text { Conventional machine } \\
\text { learning methods } \\
\text { Deep learning } \\
\text { techniques }\end{array}$ & 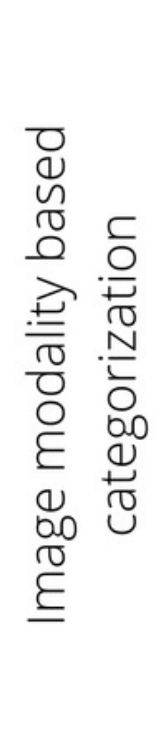 & $\begin{array}{c}\begin{array}{c}\text { Periapical X-rays } \\
\text { images } \\
\text { Bitewing X-rays } \\
\text { images }\end{array} \\
\text { Panoramic X-rays } \\
\text { CBCT or CT images } \\
\text { Hybrid datasets } \\
\text { Colour images, etc. }\end{array}$ \\
\hline
\end{tabular}


Figure 5

Traditional model used for dental image segmentation and classification

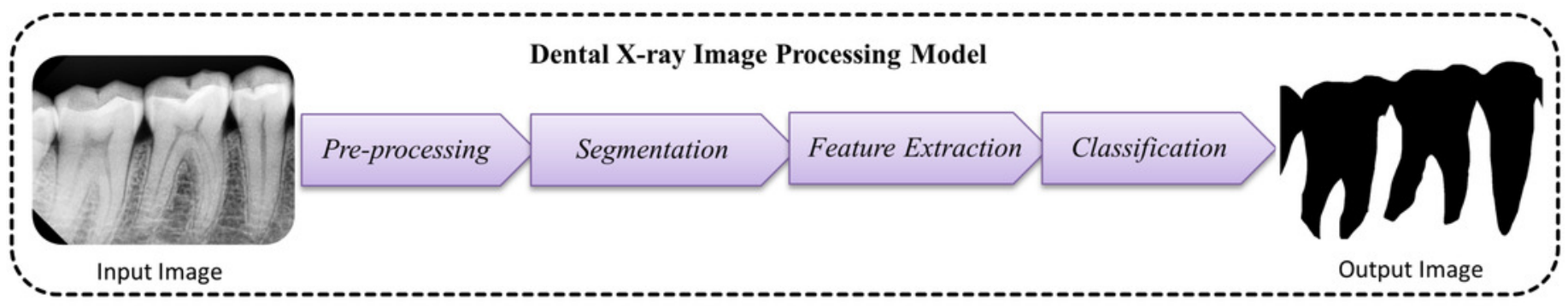


Figure 6

Purpose of segmentation \& problems in dental imaging

\section{Purpose of Dental Image Segmentation}

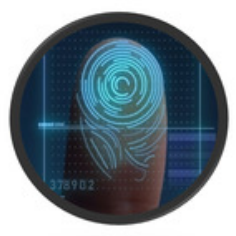

Biometrics

(Human

identification)

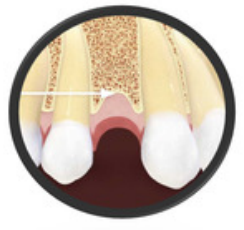

Bone loss \& Teeth gap areas

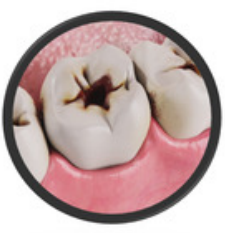

Caries detection

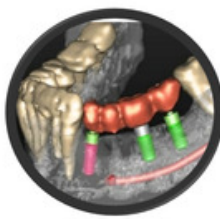

Computer guided treatment

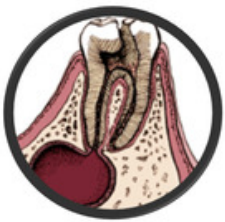

Cyst or Tumour extraction

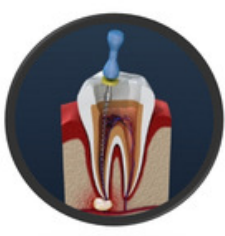

Root canal treatment diagnosis

\section{Problems in Dental Image Segmentation}

Poor image quality due to presence of noise.
Intensity

variations

in X-Ray
Proper selection of methods

for the application
Limitation

of capturing devices
Lack of availability of datasets 


\section{Figure 7}

Overview of machine learning algorithms

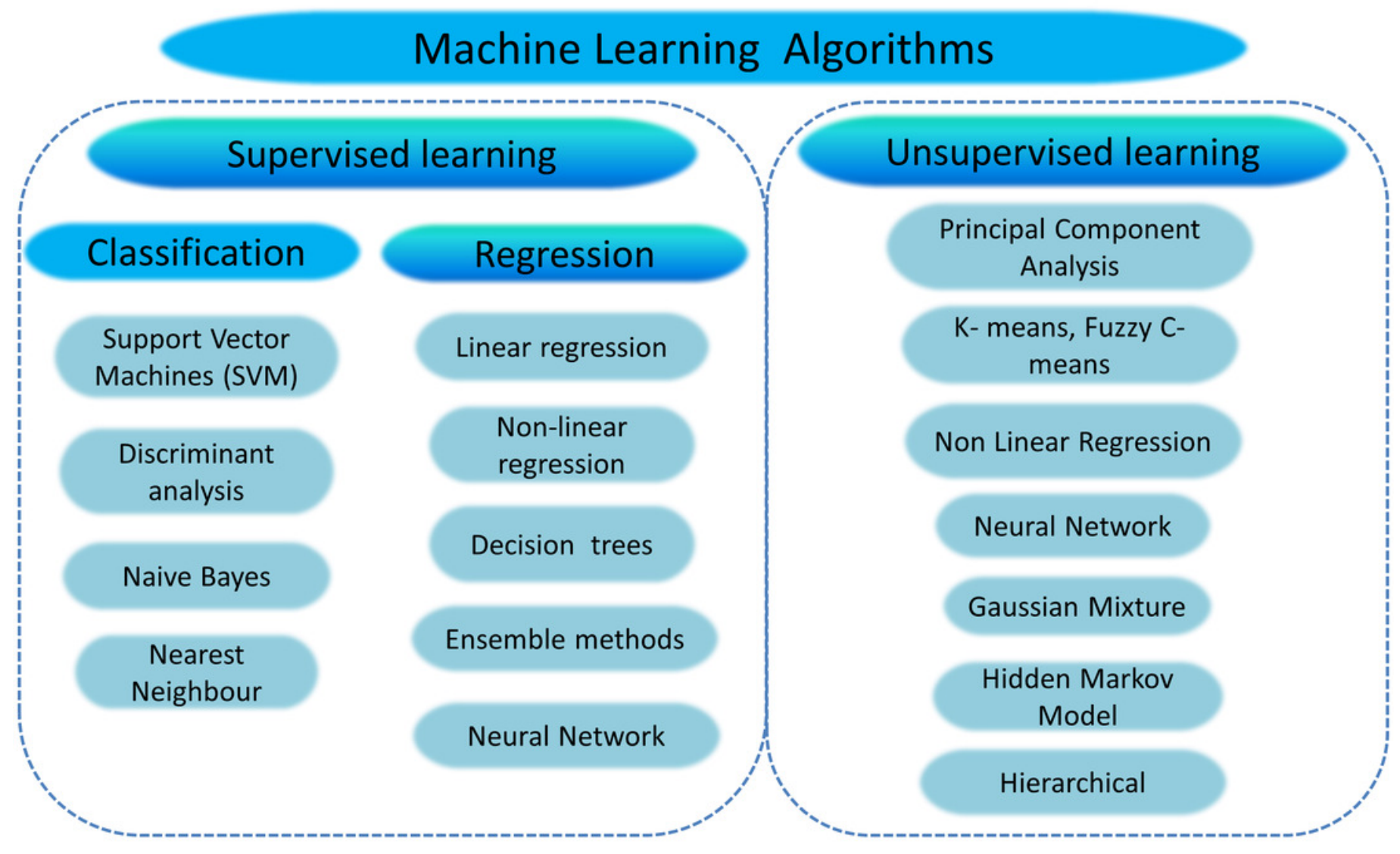


Figure 8

Performances measure comparisons used for deep learning methods

Comparison of deep learning performance metrics

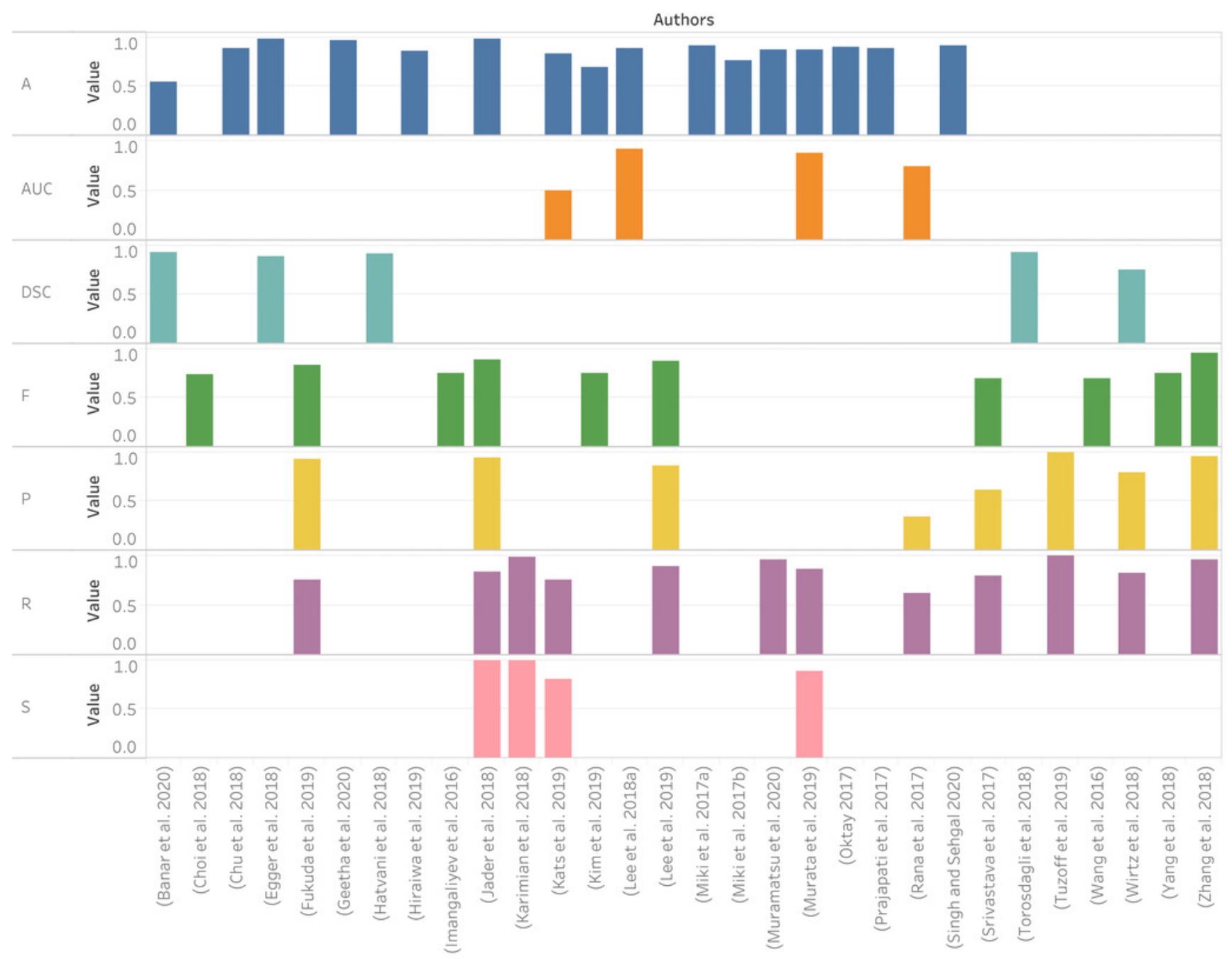




\section{Table $\mathbf{1}$ (on next page)}

Number of articles categorized based on imaging modalities 


\begin{tabular}{|c|c|}
\hline Image modalities & Number of articles published \\
\hline Periapical X-ray images & 30 \\
\hline Bitewing X-ray images & 11 \\
\hline Panoramic X-ray images & 39 \\
\hline CBCT or CT images & 13 \\
\hline Photographic Color Images & 06 \\
\hline Hybrid Dataset & 19 \\
\hline Image dataset not defined & 07 \\
\hline
\end{tabular}

1 


\section{Table 2 (on next page)}

Pre-processing methods used for dental imaging modality 


\begin{tabular}{|c|c|}
\hline Author \& Year & Enhancement / Noise removal Technique \\
\hline \multicolumn{2}{|r|}{ Methods used for Bitewing X-ray } \\
\hline (Lai \& Lin, 2008) & $\begin{array}{l}\text { Adaptive Local Contrast Stretching is used to make the tooth region smoother after that, and } \\
\text { adaptive morphological enhancement is applied to improve the texture values. }\end{array}$ \\
\hline (Prajapati, Desai \& Modi, 2012) & A median filter is used to eradicate picture impulse noise. \\
\hline $\begin{array}{l}\text { (Mahoor \& Abdel-Mottaleb, 2004; Zhou \& } \\
\text { Abdel-Mottaleb, 2005; Huang et al., 2012) }\end{array}$ & $\begin{array}{l}\text { Top hat and bottom hat filters are applied where the teeth become brightened, and the bone } \\
\text { and shadow regions obscured. }\end{array}$ \\
\hline $\begin{array}{l}\text { (Pushparaj, Gurunathan \& Arumugam, } \\
\text { 2013) }\end{array}$ & $\begin{array}{l}\text { Butterworth high pass filter used with a homomorphic filter. In which homomorphic filter } \\
\text { compensates the effect of non-uniform illumination. }\end{array}$ \\
\hline \multicolumn{2}{|r|}{ Methods used for Periapical X-ray } \\
\hline (Harandi \& Pourghassem, 2011) & $\begin{array}{l}\text { Histogram equalization and noise reduction with wavelets, use of spatial filters like } \\
\text { Laplacian filter. }\end{array}$ \\
\hline (Lin, Huang \& Huang, 2012) & Average filter with $25 * 25$ mask then histogram equalization is used. \\
\hline $\begin{array}{l}\text { (Nuansanong, Kiattisin \& Leelasantitham, } \\
\text { 2014) }\end{array}$ & Gaussian spatial filter with kernel size $5 * 5$ and sigma value 1.4 is fixed. \\
\hline (Lin et al., 2014) & $\begin{array}{l}\text { Enhancement is done by combining adaptive power law transformation, local singularity, } \\
\text { and bilateral filter. }\end{array}$ \\
\hline (Rad et al., 2015) & Median filtering is applied to enhance the images \\
\hline (Purnama et al., 2015) & $\begin{array}{l}\text { Contrast stretching used to improve the X-ray quality so that it can be easily interpreted and } \\
\text { examined correctly }\end{array}$ \\
\hline (Jain \& Chauhan, 2017) & $\begin{array}{l}\text { Gaussian filtering employed to make a more smoothed gradient nearby the edges also helps } \\
\text { in reducing noise. }\end{array}$ \\
\hline $\begin{array}{l}\text { (Obuchowicz Rafałand Nurzynska et al., } \\
\text { 2018) }\end{array}$ & Histogram equalization (HEQ) and a statistical dominance algorithm (SDA) are initiated. \\
\hline (Singh \& Agarwal, 2018) & $\begin{array}{l}\text { Median filtering is used to lower noise, and an unsharp marking filter is used to enhance the } \\
\text { high-frequency component. }\end{array}$ \\
\hline (Datta, Chaki \& Modak, 2019) & Local averaging is used to eliminate noisy features. \\
\hline (Kumar, Bhadauria \& Singh, 2020) & $\begin{array}{l}\text { The guided filter is applied with a window size of } 3 * 3 \text { and is cast-off towards calculating } \\
\text { output pixel size. }\end{array}$ \\
\hline \multicolumn{2}{|r|}{ Methods used for Panoramic X-rays } \\
\hline (Frejlichowski \& Wanat, 2011) & $\begin{array}{l}\text { Some basic filters are added to select pyramid layers, including sharpening filter and } \\
\text { contrast adjustment before image recomposition. }\end{array}$ \\
\hline (Vijayakumari et al., 2012) & Block analysis and contrast stretching applied. \\
\hline (Pushparaj et al., 2013) & $\begin{array}{l}\text { In this paper, the integration of the Butterworth bandpass filter and the homomorphic filter } \\
\text { is used to enhance the edges and illumination. }\end{array}$ \\
\hline (Razali et al., 2014) & Canny edge detection is applied, where the gaussian filter is used to eliminate the noise. \\
\hline (Banu et al., 2014) & $\begin{array}{l}\text { Image inverse and contrast stretching procedures have been used to identify the region of } \\
\text { interest. }\end{array}$ \\
\hline (Amer \& Aqel, 2015) & $\begin{array}{l}\text { Contrast enhancement with intensity transformations is used to improve the segmentation } \\
\text { procedure. }\end{array}$ \\
\hline (Poonsri et al., 2016) & Image enhancement using adaptive thresholding (Bradley \& Roth, 2007). \\
\hline (Veena Divya, Jatti \& Revan Joshi, 2016) & $\begin{array}{l}\text { The image contrast is balanced to enhance the picture's appearance and to visualize the cyst } \\
\text { or tumor. }\end{array}$ \\
\hline (Zak et al., 2017) & $\begin{array}{l}\text { A combination of top hat/bottom hat filter and adaptive power-law transformation(APLT) is } \\
\text { used to enhance images. }\end{array}$ \\
\hline (Alsmadi, 2018) & Speckle noise is reduced by using a median filter. \\
\hline (Divya et al., 2019) & $\begin{array}{l}\text { Negative transformation applied and caries identified by using the difference of contrast } \\
\text { improved Image and image negative. }\end{array}$ \\
\hline (Banday \& Mir, 2019) & Adaptive histogram equalization (CLAHE) and Median Filtering are combinedly applied. \\
\hline (Fariza et al., 2019) & $\begin{array}{l}\text { Dental X-ray image is processed using CLAHE, and gamma correction is done to improve } \\
\text { the contrast. }\end{array}$ \\
\hline (Avuçlu \& Bacsçiftçi, 2020) & Median softening filter applied after contrast stretching. \\
\hline \multicolumn{2}{|r|}{ Methods used for Hybrid Dataset } \\
\hline (Said et al., 2006) & $\begin{array}{l}\text { Internal noise is reduced by closing top-hat transformation, which is described by } \\
\text { subtracting the picture from its morphological closure. }\end{array}$ \\
\hline (Tuan, Ngan \& others, 2016) & $\begin{array}{l}\text { Background noise is minimized using a Gaussian filter; then, a Gaussian(DoG) filter is used } \\
\text { to measure the gradient along the } \mathrm{x} \text { and y-axis. }\end{array}$ \\
\hline \multicolumn{2}{|r|}{ Methods used for Color Images } \\
\hline (Ghaedi et al., 2014) & A contrast enhancement focused on the histogram is introduced to the gray-level Image. \\
\hline (Datta \& Chaki, 2015a) & Denoising is done by using a wiener filter. \\
\hline (Datta \& Chaki, 2015b) & A Wiener filter is applied to eliminate the blurring effect and additive noise. \\
\hline (Berdouses et al., 2015) & Gray level transformation performed. \\
\hline \multicolumn{2}{|r|}{ Methods used for CBCT \& CT } \\
\hline
\end{tabular}




\begin{tabular}{|l|l|}
\hline (Benyó et al., 2009) & Image with high-frequency noise are enhanced by applying a median filter \\
\hline (Ji, Ong \& Foong, 2014) & $\begin{array}{l}\text { Initially, the Intensity range was adjusted, followed by Gaussian filtering with a standard } \\
\text { deviation to suppress noise. }\end{array}$ \\
\hline
\end{tabular}

1 


\section{Table 3 (on next page)}

Review findings of the image processing techniques using different imaging modalities 


\begin{tabular}{|c|c|c|c|}
\hline Author \& Year & Relevant review findings & Total images & Detection/Identification \\
\hline \multicolumn{4}{|c|}{ Imaging modality: Bitewing X-rays } \\
\hline $\begin{array}{l}\text { (Mahoor \& Abdel- } \\
\text { Mottaleb, 2004) }\end{array}$ & $\begin{array}{l}\text { For Segmentation, adaptive thresholding methods is being used, } \\
\text { then features are extracted, and teeth numbering is done using } \\
\text { the Bayesian classification technique. }\end{array}$ & 50 & Teeth numbering \\
\hline $\begin{array}{l}\text { (Zhou \& Abdel- } \\
\text { Mottaleb, 2005) }\end{array}$ & $\begin{array}{l}\text { Proposed Segmentation using a window-based adaptive } \\
\text { thresholding scheme and minimum Hausdorff distance used for } \\
\text { matching purposes }\end{array}$ & $\begin{array}{l}\text { Training }=102 \\
\text { images } \\
\text { Testing }=40 \\
\text { images }\end{array}$ & Human identification \\
\hline $\begin{array}{l}\text { (Nomir \& Abdel- } \\
\text { Mottaleb, 2005) }\end{array}$ & $\begin{array}{l}\text { Results are improved by using a signature vector in conjunction } \\
\text { with adaptive and iterative thresholding. }\end{array}$ & 117 & Human identification \\
\hline $\begin{array}{l}\text { (Nomir \& Abdel- } \\
\text { Mottaleb, 2007) }\end{array}$ & $\begin{array}{l}\text { Iterative followed by adaptive thresholding used for the } \\
\text { Segmentation and features extracted using fourier descriptors } \\
\text { after forcefield transformation then matching is done by using } \\
\text { euclidian distance }\end{array}$ & 162 & Human identification \\
\hline (Lai \& Lin, 2008) & $\begin{array}{l}\text { The B-spline curve is used to extract intensity and texture } \\
\text { characteristics for K-means clustering to locate the bones and } \\
\text { teeth contour. }\end{array}$ & N.A & Teeth detection \\
\hline $\begin{array}{l}\text { (Nomir \& Abdel- } \\
\text { Mottaleb, 2008) }\end{array}$ & $\begin{array}{l}\text { The procedure starts with an iterative process guided by adaptive } \\
\text { thresholding. Finally, the Bayesian framework is employed for } \\
\text { tooth matching. }\end{array}$ & 187 & Human identification \\
\hline $\begin{array}{l}\text { (Harandi, } \\
\text { Pourghassem \& } \\
\text { Mahmoodian, 2011) }\end{array}$ & $\begin{array}{l}\text { An active geodesic contour is employed for upper and lower } \\
\text { jaws segmentation. }\end{array}$ & 14 & Jaw identification \\
\hline (Huang et al., 2012) & $\begin{array}{l}\text { An adaptive windowing scheme with isolation-curve verification } \\
\text { is used to detect missing tooth regions. }\end{array}$ & 60 & Missing teeth detection \\
\hline $\begin{array}{l}\text { (Prajapati, Desai \& } \\
\text { Modi, 2012) }\end{array}$ & $\begin{array}{l}\text { A region growing technique is applied to the X-rays to extract } \\
\text { the tooth; then, the content-based image retrieval (CBIR) } \\
\text { technique is used for matching purposes. }\end{array}$ & 30 & Human identification \\
\hline $\begin{array}{l}\text { (Pushparaj, } \\
\text { Gurunathan \& } \\
\text { Arumugam, 2013) }\end{array}$ & $\begin{array}{l}\text { The tooth area's shape is extracted using contour-based } \\
\text { connected component labeling, and the Mahalanobis distance } \\
\text { (MD) is measured for matching. }\end{array}$ & 50 & Person identification \\
\hline \multicolumn{4}{|c|}{ Imaging modality: Periapical X-rays } \\
\hline (Huang \& Hsu, 2008) & $\begin{array}{l}\text { Binary image transformations, thresholding, quartering, } \\
\text { characterization, and labeling were all used as part of the } \\
\text { process. }\end{array}$ & 420 & Teeth detection \\
\hline (Oprea et al., 2008) & $\begin{array}{l}\text { Simple thresholding technique applied for Segmentation of } \\
\text { caries. }\end{array}$ & N.A & Caries detection \\
\hline $\begin{array}{l}\text { (Harandi \& } \\
\text { Pourghassem, 2011) }\end{array}$ & $\begin{array}{l}\text { Otsu thresholding method with canny edge detection is used to } \\
\text { segment the root canal area. }\end{array}$ & 43 & Root canal detection \\
\hline $\begin{array}{l}\text { (Lin, Huang \& } \\
\text { Huang, 2012) }\end{array}$ & $\begin{array}{l}\text { The lesion is detected using a variational level set method after } \\
\text { applying otsu's method. }\end{array}$ & 6 & Lesion detection \\
\hline $\begin{array}{l}\text { (Sattar \& Karray, } \\
\text { 2012) }\end{array}$ & $\begin{array}{l}\text { Phase congruency based approach is used to provide a } \\
\text { framework for local image structure }+ \text { edge detection }\end{array}$ & N.A & Teeth detection \\
\hline $\begin{array}{l}\text { (Niroshika, Meegama } \\
\& \text { Fernando, 2013) }\end{array}$ & $\begin{array}{l}\text { Deformation and re-parameterize are added to the contour to } \\
\text { detect the tooth comer points. }\end{array}$ & N.A & Teeth detection \\
\hline $\begin{array}{l}\text { (Ayuningtiyas et al., } \\
2013 \text { ) }\end{array}$ & $\begin{array}{l}\text { Dentin and pulp are separated using active contour, and } \\
\text { qualitative analysis is conducted using the dentist's visual } \\
\text { inspection, while quantitative testing is done by measuring } \\
\text { different statistic parameters. }\end{array}$ & N.A & Tooth detection \\
\hline $\begin{array}{l}\text { (Nuansanong, } \\
\text { Kiattisin \& } \\
\text { Leelasantitham, 2014) }\end{array}$ & $\begin{array}{l}\text { Canny edge detection was initially used, followed by an active } \\
\text { contour model with data mining (J48 tree) and integration with } \\
\text { the competence path. }\end{array}$ & Approx. 50 & Tooth detection \\
\hline (Lin et al., 2014) & $\begin{array}{l}\text { The otsu's threshold and connected component analysis are used } \\
\text { to precisely segment the teeth from alveolar bones and remove } \\
\text { false teeth areas. }\end{array}$ & 28 & Teeth detection \\
\hline (Purnama et al., 2015) & $\begin{array}{l}\text { For root canal segmentation, an active shape model and thinning } \\
\text { (using a hit-and-miss transform) were used. }\end{array}$ & 7 & Root canal detection \\
\hline (Rad et al., 2015) & $\begin{array}{l}\text { The Segmentation is initially done using K-means clustering. } \\
\text { Then, using a gray-level co-occurrence matrix, characteristics } \\
\text { were extracted from the X-rays. }\end{array}$ & 32 & Caries detection \\
\hline $\begin{array}{l}\text { (Jain \& Chauhan, } \\
\text { 2017) }\end{array}$ & $\begin{array}{l}\text { First, all parameter values defined in the snake model then initial } \\
\text { contour points initializes, and at last canny edge detection extract } \\
\text { the affected part. }\end{array}$ & N.A & Cyst detection \\
\hline $\begin{array}{l}\text { (Singh \& Agarwal, } \\
\text { 2018) }\end{array}$ & $\begin{array}{l}\text { The color to mark the carious lesion is provided by the contrast } \\
\text { limited adaptive histogram (CLAHE) technique combined with } \\
\text { masking. }\end{array}$ & 23 & Caries detection \\
\hline (Rad et al., 2018) & The level set segmentation process (LS) is used in two stages. & 120 & Caries detection \\
\hline
\end{tabular}




\begin{tabular}{|c|c|c|c|}
\hline & $\begin{array}{l}\text { The first stage is the initial contour creation to create the most } \\
\text { appropriate IC, and the second stage is the artificial neural } \\
\text { network-based smart level approach. }\end{array}$ & & \\
\hline $\begin{array}{l}\text { (Obuchowicz } \\
\text { Rafałand Nurzynska } \\
\text { et al., 2018) }\end{array}$ & $\begin{array}{l}\text { K-means clustering applied considering intensity values and } \\
\text { first-order features (FOF) detect the caries spots }\end{array}$ & 10 & Caries detection \\
\hline $\begin{array}{l}\text { (Devi, Banumathi \& } \\
\text { Ulaganathan, 2019) }\end{array}$ & $\begin{array}{l}\text { The hybrid algorithm is applied using isophote curvature and the } \\
\text { fast marching method (FMM) to extract the cyst. }\end{array}$ & 3 & Cyst detection \\
\hline $\begin{array}{l}\text { (Datta, Chaki \& } \\
\text { Modak, 2019) }\end{array}$ & $\begin{array}{l}\text { The geodesic active contour method is applied to identify the } \\
\text { dental caries lesion. }\end{array}$ & 120 & Caries detection \\
\hline $\begin{array}{l}\text { (Osterloh \& Viriri, } \\
\text { 2019) }\end{array}$ & $\begin{array}{l}\text { Proposed unsupervised model to extract the caries region. Jaws } \\
\text { partition is done using thresholding and an integral projection } \\
\text { algorithm. The top and bottom hats, as well as active contours, } \\
\text { were used to detect caries borders. }\end{array}$ & N.A & Caries detection \\
\hline $\begin{array}{l}\text { (Kumar, Bhadauria \& } \\
\text { Singh, 2020) }\end{array}$ & $\begin{array}{l}\text { The various dental structures were separated using the fuzzy C- } \\
\text { means algorithm and the hyperbolic tangent gaussian kernel } \\
\text { function. }\end{array}$ & 152 & Dental structures \\
\hline $\begin{array}{l}\text { (Datta, Chaki \& } \\
\text { Modak, 2020) }\end{array}$ & $\begin{array}{l}\text { This method converts the X-ray image data into its neutrosophic } \\
\text { analog domain. A custom feature called 'weight' is used for } \\
\text { neutrosophication. Contrary to popular belief, this feature is } \\
\text { determined by merging other features. }\end{array}$ & 120 & Caries detection \\
\hline \multicolumn{4}{|c|}{ Imaging Modality: Panoramic X-rays } \\
\hline $\begin{array}{l}\text { (Patanachai, } \\
\text { Covavisaruch \& } \\
\text { Sinthanayothin, 2010) }\end{array}$ & $\begin{array}{l}\text { The wavelet transform, thresholding segmentation, and adaptive } \\
\text { thresholding segmentation are all compared. Where, the results } \\
\text { of wavelet transform show better accuracy as compare to others. }\end{array}$ & N.A & Teeth detection \\
\hline $\begin{array}{l}\text { (Frejlichowski \& } \\
\text { Wanat, 2011) }\end{array}$ & $\begin{array}{l}\text { An automatic human identification system applies a horizontal } \\
\text { integral projection to segment the individual tooth in this } \\
\text { approach. }\end{array}$ & 218 & Human identification \\
\hline $\begin{array}{l}\text { (Vijayakumari et al., } \\
\text { 2012) }\end{array}$ & $\begin{array}{l}\text { A gray level co-occurrence matrix is used to detect the cyst } \\
\text { (GLCM). }\end{array}$ & 3 & Cyst detection \\
\hline $\begin{array}{l}\text { (Pushparaj et al., } \\
\text { 2013) }\end{array}$ & $\begin{array}{l}\text { Horizontal integral projection with a B-spline curve is employed } \\
\text { to separate maxilla and mandible }\end{array}$ & N.A & Teeth numbering \\
\hline (Lira et al., 2014) & $\begin{array}{l}\text { Supervised learning used for segmentation and feature extraction } \\
\text { is carried out through computing moments and statistical } \\
\text { characteristics. At last, the bayesian classifier is used to identify } \\
\text { different classes. }\end{array}$ & 1 & Teeth detection \\
\hline (Banu et al., 2014) & $\begin{array}{l}\text { The gray level co-occurrence matrix is used to compute texture } \\
\text { characteristics (GLCM) and classification results obtained in the } \\
\text { feature space, focusing on the centroid and K-mean classifier. }\end{array}$ & 23 & Cyst detection \\
\hline (Razali et al., 2014) & $\begin{array}{l}\text { This study aims to compare the edge segmentation } \\
\text { methods: Canny and Sobel on X-ray images. }\end{array}$ & N.A & Teeth detection \\
\hline (Amer \& Aqel, 2015) & $\begin{array}{l}\text { The segmentation process uses the global Ots's thresholding } \\
\text { technique with linked component labeling. The ROI extraction } \\
\text { and post-processing are completed at the end. }\end{array}$ & 1 & Wisdom teeth detection \\
\hline $\begin{array}{l}\text { (Abdi, Kasaei \& } \\
\text { Mehdizadeh, 2015) }\end{array}$ & $\begin{array}{l}\text { Four stages used for Segmentation: Gap valley extraction, canny } \\
\text { edge with morphological operators, contour tracing, and } \\
\text { template matching. }\end{array}$ & 95 & Mandible detection \\
\hline $\begin{array}{l}\text { (Veena Divya, Jatti \& } \\
\text { Revan Joshi, 2016) }\end{array}$ & Active contour or snake model used to detect the cyst boundary. & 10 & Cyst detection \\
\hline (Poonsri et al., 2016) & $\begin{array}{l}\text { Teeth identification, template matching using correlation, and } \\
\text { area segmentation using K-means clustering are used. }\end{array}$ & 25 & Teeth detection \\
\hline (Zak et al., 2017) & $\begin{array}{l}\text { Individual arc teeth segmentation (IATS) with adaptive } \\
\text { thresholding is applied to find the palatal bone. }\end{array}$ & 94 & Teeth detection \\
\hline (Alsmadi, 2018) & $\begin{array}{l}\text { In panoramic X-ray images that can help in diagnosing jaw } \\
\text { lesions, the fuzzy C-means concept and the neutrosophic } \\
\text { technique are combinedly used to segment jaw pictures and } \\
\text { locate the jaw lesion region. }\end{array}$ & 60 & Lesion detection \\
\hline $\begin{array}{l}\text { (Dibeh, Hilal \& } \\
\text { Charara, 2018) }\end{array}$ & $\begin{array}{l}\text { The methods use a shape-free layout fitted into a 9-degree } \\
\text { polynomial curve to segment the area between the maxillary and } \\
\text { mandibular jaws. }\end{array}$ & 62 & $\begin{array}{l}\text { Jaw separation+teeth } \\
\text { detection }\end{array}$ \\
\hline $\begin{array}{l}\text { (Mahdi \& Kobashi, } \\
\text { 2018) }\end{array}$ & $\begin{array}{l}\text { Quantum Particle Swarm Optimization (QPSO) is employed for } \\
\text { multilevel thresholding. }\end{array}$ & 12 & Teeth detection \\
\hline (Ali et al., 2018) & $\begin{array}{l}\text { A new clustering method based on the neutrosophic orthogonal } \\
\text { matrix is presented to help in the extraction of teeth and jaws } \\
\text { areas from panoramic X-rays. }\end{array}$ & 66 & Teeth detection \\
\hline (Divya et al., 2019) & $\begin{array}{l}\text { Textural details extracted using GLCM to classify the cyst and } \\
\text { caries. }\end{array}$ & 10 & $\begin{array}{l}\text { Dental caries \& cyst } \\
\text { extraction }\end{array}$ \\
\hline (Banday \& Mir, 2019) & Edge detection method for the Segmentation then, the & 210 & Human identification \\
\hline
\end{tabular}




\begin{tabular}{|c|c|c|c|}
\hline & $\begin{array}{l}\text { Autoregression(AR) model is adopted, and AR coefficients are } \\
\text { derived from the feature vector. At last, matching is performed } \\
\text { using euclidean distance. }\end{array}$ & & \\
\hline (Fariza et al., 2019) & $\begin{array}{l}\text { For tooth segmentation, the Gaussian kernel-based conditional } \\
\text { spatial fuzzy c-means (GK-csFCM) clustering algorithm is used. }\end{array}$ & 10 & Teeth detection \\
\hline (Aliaga et al., 2020) & $\begin{array}{l}\text { The region of interest is extracted from the entire X-ray image, } \\
\text { and Segmentation is performed using k-means clustering. }\end{array}$ & 370 & $\begin{array}{l}\text { Osteoporosis detection, } \\
\text { mandible detection }\end{array}$ \\
\hline $\begin{array}{l}\text { (Avuçlu \& Bacsçiftçi, } \\
\text { 2020) }\end{array}$ & $\begin{array}{l}\text { The Image is converted to binary using Otsu's thresholding, and } \\
\text { then a canny edge detector is used to find the object of interest. }\end{array}$ & 1315 & $\begin{array}{l}\text { Determination of age and } \\
\text { gender }\end{array}$ \\
\hline \multicolumn{4}{|c|}{ Imaging modality: Hybrid dataset images } \\
\hline (Said et al., 2006) & $\begin{array}{l}\text { Thresholding with mathematical morphology is performed for } \\
\text { the Segmentation. }\end{array}$ & $\begin{array}{l}500 \text { Bitewing } \\
\& 130 \\
\text { Periapical } \\
\text { images. }\end{array}$ & Teeth detection \\
\hline (Li et al., 2006) & $\begin{array}{l}\text { The fast and accurate segmentation approach used strongly } \\
\text { focused on mathematical morphology and shape analysis. }\end{array}$ & $\begin{array}{l}500 \text { (Bitewing } \\
\text { and Periapical } \\
\text { images) }\end{array}$ & Person identification \\
\hline $\begin{array}{l}\text { (Al-sherif, Guo \& } \\
\text { Ammar, 2012) }\end{array}$ & $\begin{array}{l}\text { A two-phase threshold processing is used, starting with an } \\
\text { iterative threshold followed by an adaptive threshold to binarize } \\
\text { teeth images after separating the individual tooth using the seam } \\
\text { carving method. }\end{array}$ & $\begin{array}{l}500 \text { Bitewing } \\
\& 130 \\
\text { Periapical } \\
\text { images }\end{array}$ & Teeth detection \\
\hline $\begin{array}{l}\text { (Ali, Ejbali \& Zaied, } \\
\text { 2015) }\end{array}$ & $\begin{array}{l}\text { The Chan-vese model and an active contour without edges are } \\
\text { used to divide an image into two regions with piece-constant } \\
\text { intensities. }\end{array}$ & N.A & Teeth detection \\
\hline (Tuan \& others, 2016) & $\begin{array}{l}\text { The otsu threshold procedure, fuzzy C-means, and semi- } \\
\text { supervised fuzzy clustering are all part of a collaborative } \\
\text { framework (eSFCM). }\end{array}$ & $\begin{array}{l}8 \& 56 \text { Image } \\
\text { dataset } \\
\text { (Bitewing }+ \\
\text { Panoramic) }\end{array}$ & Teeth structures \\
\hline $\begin{array}{l}\text { (Tuan, Ngan \& others, } \\
\text { 2016) }\end{array}$ & $\begin{array}{l}\text { It uses a semi-supervised fuzzy clustering algorithm - SSFC-FS } \\
\text { based on the Interactive Fuzzy Satisficing method. }\end{array}$ & $\begin{array}{l}56 \text { (Periapical } \\
\& \text { Panoramic) }\end{array}$ & Teeth structures \\
\hline $\begin{array}{l}\text { (Tuan \& others, } \\
\text { 2017) }\end{array}$ & $\begin{array}{l}\text { Semi-supervised fuzzy clustering algorithm combined with } \\
\text { spatial constraints (SSFC-SC) for dental image segmentation. }\end{array}$ & $\begin{array}{l}56 \text { (Periapical } \\
\text { \& panoramic } \\
\text { images) }\end{array}$ & Teeth structures \\
\hline (Tuan et al., 2018) & $\begin{array}{l}\text { Graph-based clustering algorithm called enhanced affinity } \\
\text { propagation clustering (APC) used for classification process and } \\
\text { fuzzy aggregation operators used for disease detection. }\end{array}$ & $\begin{array}{l}87 \text { (Periapical } \\
\& \text { Panoramic) }\end{array}$ & Disease detection \\
\hline \multicolumn{4}{|c|}{ Imaging modality: Photographic color images } \\
\hline (Ghaedi et al., 2014) & $\begin{array}{l}\text { Segmentation functions in two ways. In the first step, the tooth } \\
\text { surface is partitioned using a region-widening approach and the } \\
\text { Circular Hough Transform (CHT). The second stage uses } \\
\text { morphology operators to quantify texture to define the abnormal } \\
\text { areas of the tooth's boundaries. Finally, a random forest } \\
\text { classifies the various classes. }\end{array}$ & 88 & Caries detection \\
\hline $\begin{array}{l}\text { (Datta \& Chaki, } \\
\text { 2015a) }\end{array}$ & $\begin{array}{l}\text { They have proposed a biometrics dental technique using RGB } \\
\text { images. Segment individual teeth with water Shed and Snake's } \\
\text { help, then afterward incisors teeth features are obtained to } \\
\text { identify the human. }\end{array}$ & $\begin{array}{l}270 \text { Images } \\
\text { dataset }\end{array}$ & Person identification \\
\hline $\begin{array}{l}\text { (Datta \& Chaki, } \\
2015 \text { b) }\end{array}$ & $\begin{array}{l}\text { The proposed method introduces a method for filtering optical } \\
\text { teeth images and extracting caries lesions followed by cluster- } \\
\text { based Segmentation. }\end{array}$ & 45 & Caries detection \\
\hline $\begin{array}{l}\text { (Berdouses et al., } \\
\text { 2015) }\end{array}$ & $\begin{array}{l}\text { The proposed scheme included two processes: (a) identification, } \\
\text { in which regions of interest (pre-cavitated and cavitated occlusal } \\
\text { lesions) were partitioned, and (b) classification, in which the } \\
\text { identified zones were categorized into one of the seven ICDAS } \\
\text { classes. }\end{array}$ & 103 & Caries detection \\
\hline \multicolumn{4}{|c|}{ Imaging modality: CT \& CBCT } \\
\hline (Gao \& Chae, 2008) & $\begin{array}{l}\text { The multi-step procedure using thresholding, dilation, connected } \\
\text { component labeling, upper-lower jaw separation, and last arch } \\
\text { curve fitting was used to find the tooth region. }\end{array}$ & N.A & Teeth detection \\
\hline $\begin{array}{l}\text { (Hosntalab et al., } \\
2010)\end{array}$ & $\begin{array}{l}\text { Otsu thresholding, morphological operations, and panoramic re- } \\
\text { sampling, and variational level set were used. Following that, } \\
\text { feature extraction with a wavelet-Fourier descriptor (WFD) and } \\
\text { a centroid distance signature is accomplished. Finally, multilayer } \\
\text { perceptron (MLP), Kohonen self-organizing network, and hybrid } \\
\text { structure are used for Classification. }\end{array}$ & $\begin{array}{l}30 \text { Multislice } \\
\text { CT image } \\
\text { (MSCT) } \\
\text { dataset consists } \\
\text { of } 804 \text { teeth }\end{array}$ & $\begin{array}{l}\text { Teeth detection and } \\
\text { Classification }\end{array}$ \\
\hline (Gao \& Chae, 2010) & $\begin{array}{l}\text { An adaptive active contour tracking algorithm is used. In which } \\
\text { the root is tracked using a single level set technique. In addition, }\end{array}$ & $18 \mathrm{CT}$ images & Teeth detection \\
\hline
\end{tabular}




\begin{tabular}{|l|l|l|l|}
\hline & the variational level was increased in several ways. & & Teeth detection \\
\hline $\begin{array}{l}\text { (Mortaheb, Rezaeian } \\
\text { 2013) }\end{array}$ & $\begin{array}{l}\text { Mean shift algorithm is used for CBCT segmentation with new } \\
\text { feature space and is compared to thresholding, watershed, level } \\
\text { set, and active contour techniques. }\end{array}$ & $\begin{array}{l}2 \mathrm{CBCT} \\
\text { images }\end{array}$ & Teeth detection \\
\hline Gao \& Li, 2013) & $\begin{array}{l}\text { The volume data are initially divided into homogeneous blocks } \\
\text { and then iteratively merged to produce the initial labeled and } \\
\text { unlabeled instances for semi-supervised study. }\end{array}$ & N.A & Teeth structure \\
\hline $\begin{array}{l}\text { (Ji, Ong \& Foong, } \\
\text { 2014) }\end{array}$ & $\begin{array}{l}\text { The study adds a new level set procedure for extracting the } \\
\text { integrates the objective functions of existing level set methods } \\
\text { with a twofold intensity model. }\end{array}$ & $\begin{array}{l}10 \mathrm{CBCT} \\
\text { images }\end{array}$ \\
\hline (Hu et al., 2014) & $\begin{array}{l}\text { Otsu and mean thresholding technique combinedly used to } \\
\text { improve the Segmentation. }\end{array}$ & $\begin{array}{l}\text { Image dataset } \\
\text { consists of } 300 \\
\text { layers }\end{array}$ & Teeth detection \\
\hline
\end{tabular}




\section{Table 4 (on next page)}

The table shows relevant review findings of conventional machine learning algorithms for different imaging modalities 


\begin{tabular}{|c|c|c|c|c|}
\hline Author \& Year & Relevant review findings & Images & Feature classifier & Detection \\
\hline \multicolumn{5}{|c|}{ Imaging odality: Periapical X-rays } \\
\hline $\begin{array}{l}\text { (Li et al., 2005, } \\
\text { 2007) }\end{array}$ & $\begin{array}{l}\text { To segment the dental Image into normal, } \\
\text { abnormal, and potentially abnormal areas, } \\
\text { the variational level set function is used.. }\end{array}$ & $60 \mathrm{X}$-rays & $\begin{array}{l}\text { Trained SVM is used to } \\
\text { characterize the normal and } \\
\text { abnormal regions after } \\
\text { Segmentation. }\end{array}$ & $\begin{array}{l}\text { Bone loss \& } \\
\text { root decay }\end{array}$ \\
\hline \multicolumn{5}{|c|}{ Imaging modality: Panoramic X-rays } \\
\hline $\begin{array}{l}\text { (Pushparaj et } \\
\text { al., 2013) }\end{array}$ & $\begin{array}{l}\text { The geometrical features are used to classify } \\
\text { both premolar and molar teeth, while for } \\
\text { tooth numbering, the matching templates } \\
\text { method is used effectively. }\end{array}$ & N.A & \begin{tabular}{lr}
\multicolumn{3}{l}{ Feature extraction } & (Projected \\
principal edge & distribution \\
(PPED) + & Geometric \\
properties + & Region \\
descriptors) + SVM &
\end{tabular} & $\begin{array}{l}\text { Teeth } \\
\text { numbering } \\
\text { and } \\
\text { Classification } \\
\text { are used to } \\
\text { help Forensic } \\
\text { odontologists. }\end{array}$ \\
\hline $\begin{array}{l}\text { (Sornam \& } \\
\text { Prabhakaran, } \\
\text { 2017) }\end{array}$ & $\begin{array}{l}\text { The Linearly Adaptive Particle Swarm } \\
\text { algorithm is developed and implemented to } \\
\text { improve the accuracy rate of the neural } \\
\text { system classifier. }\end{array}$ & N.A & $\begin{array}{l}\text { Back Propagation Neural } \\
\text { Network (BPNN) and } \\
\text { Linearly Adaptive Particle } \\
\text { Swarm Optimization (LA- } \\
\text { PSO) }\end{array}$ & $\begin{array}{l}\text { Caries } \\
\text { detection }\end{array}$ \\
\hline (Bo et al., 2017) & $\begin{array}{l}\text { A two-stage SVM model was proposed for } \\
\text { the Classification of osteoporosis. }\end{array}$ & $\begin{array}{l}\text { Dataset consists } \\
\text { of } 40 \text { images }\end{array}$ & $\begin{array}{l}\text { HOG (histogram of oriented } \\
\text { gradients }+ \text { SVM }\end{array}$ & $\begin{array}{l}\text { Osteoporosis } \\
\text { detection }\end{array}$ \\
\hline $\begin{array}{l}\text { (Vila-Blanco, } \\
\text { Tomás \& } \\
\text { Carreira, 2018) }\end{array}$ & $\begin{array}{l}\text { Segmentation of mandibular teeth carried out } \\
\text { by applying Random forest regression- } \\
\text { voting constrained local model (RFRV- } \\
\text { CLM) in } 2 \text { steps: The 1st step gives an } \\
\text { estimate of individual teeth and mandible } \\
\text { regions used to initialize search for the tooth. } \\
\text { In the second step, the investigation is } \\
\text { carried out separately for each tooth. }\end{array}$ & $\begin{array}{l}\text { Training images: } \\
261 \\
\text { Testing images: } \\
85\end{array}$ & (RFRV-CLMs) & $\begin{array}{l}\text { Adult age } \\
\text { teeth } \\
\text { detection or a } \\
\text { missing tooth } \\
\text { for person } \\
\text { identification. }\end{array}$ \\
\hline \multicolumn{5}{|c|}{ Imaging Modality: Photographic Color Images } \\
\hline $\begin{array}{l}\text { (Fernandez \& } \\
\text { Chang, 2012) }\end{array}$ & $\begin{array}{l}\text { Teeth segmentation and Classification of } \\
\text { teeth palate using ANN gives better results } \\
\text { as compared to SVM. It shows that ANN is } \\
\text { 7-times faster than SVM in terms of time }\end{array}$ & N.A & $\begin{array}{l}\text { ANN }+ \text { Multilayer } \\
\text { perceptrons trained with the } \\
\text { error back-propagation } \\
\text { algorithm. }\end{array}$ & $\begin{array}{l}\text { Oral infecto- } \\
\text { contagious } \\
\text { diseases, }\end{array}$ \\
\hline $\begin{array}{l}\text { (Prakash, } \\
\text { Gowsika \& } \\
\text { Sathiyapriya, } \\
\text { 2015) }\end{array}$ & $\begin{array}{l}\text { The prognosticating faults method includes } \\
\text { the following stages: pre-processing, } \\
\text { Segmentation, features extraction, SVM } \\
\text { classification, and prediction of diseases. }\end{array}$ & N.A & $\begin{array}{l}\text { Adaptive threshold + } \\
\text { Unsupervised SVM classifier }\end{array}$ & $\begin{array}{l}\text { Dental defect } \\
\text { prediction }\end{array}$ \\
\hline \multicolumn{5}{|c|}{ Imaging Modality: CBCT or CT } \\
\hline $\begin{array}{l}\text { (Yilmaz, } \\
\text { Kayikcioglu \& } \\
\text { Kayipmaz, } \\
\text { 2017) }\end{array}$ & $\begin{array}{l}\text { Classifier efficiency improved by using the } \\
\text { forward feature selection algorithm to reduce } \\
\text { the size of the feature vector. The SVM } \\
\text { classifier performs best in classifying } \\
\text { periapical cyst and keratocystic odontogenic } \\
\text { tumor (KCOT) lesions. }\end{array}$ & $\begin{array}{l}50 \text { CBCT } 3 \mathrm{D} \\
\text { scans }\end{array}$ & $\begin{array}{l}\text { Order statistics (median, } \\
\text { standard deviation, skewness, } \\
\text { kurtosis, entropy) and 3D } \\
\text { Haralick } \\
\text { Features + SVM }\end{array}$ & $\begin{array}{l}\text { Periapical } \\
\text { cyst and } \\
\text { keratocystic } \\
\text { odontogenic } \\
\text { tumor }\end{array}$ \\
\hline \multicolumn{5}{|c|}{ Imaging Modality: Hybrid Dataset Images } \\
\hline $\begin{array}{l}\text { (Nassar \& } \\
\text { Ammar, 2007) }\end{array}$ & $\begin{array}{l}\text { A hybrid learning algorithm is used to } \\
\text { evaluate the binary bayesian classification } \\
\text { filters' metrics and the class-conditional } \\
\text { intensities. }\end{array}$ & $\begin{array}{l}\text { Bitewing \& } \\
\text { Periapical films }\end{array}$ & $\begin{array}{l}\text { Feature extraction } \\
\text { Bayesian classification. }\end{array}$ & $\begin{array}{l}\text { Teeth are } \\
\text { matching for } \\
\text { forensic } \\
\text { odontology. }\end{array}$ \\
\hline $\begin{array}{l}\text { (Avuçlu \& } \\
\text { Balcsçiftçi, } \\
\text { 2019) }\end{array}$ & $\begin{array}{l}\text { Firstly, Image pre-processing and } \\
\text { Segmentation are applied to extract the } \\
\text { features and quantitative information } \\
\text { obtained from the feature extraction from } \\
\text { teeth images. Subsequently, features are } \\
\text { taken as input to the multilayer perceptron } \\
\text { neural network. }\end{array}$ & $\begin{array}{l}1315 \text { Dental X-ray } \\
\text { images, } 162 \\
\text { different age } \\
\text { groups }\end{array}$ & $\begin{array}{l}\text { Otsu thresholding }+ \text { Feature } \\
\text { extraction (average absolute } \\
\text { deviation) }+ \text { Multilayer } \\
\text { perceptron neural network }\end{array}$ & $\begin{array}{l}\text { Age and } \\
\text { gender } \\
\text { classification }\end{array}$ \\
\hline
\end{tabular}




\section{Table 5 (on next page)}

The table shows relevant review findings of deep learning algorithms for different imaging modalities 


\begin{tabular}{|c|c|c|c|}
\hline Authors & Deep learning architectures & Detection/Application & Metrics \\
\hline \multicolumn{4}{|c|}{ Imaging modality: Periapical X-rays } \\
\hline $\begin{array}{l}\text { (Prajapati, Nagaraj } \\
\& \text { Mitra, 2017) }\end{array}$ & $\mathrm{CNN}$ and transfer learning & $\begin{array}{l}\text { Dental caries, periapical } \\
\text { infection, and periodontitis }\end{array}$ & Accuracy:- 0.8846 \\
\hline (Yang et al., 2018) & Conventional CNN & Automated clinical diagnosis & F1 score 0.749 \\
\hline (Zhang et al., 2018) & $\begin{array}{l}\text { CNN (label tree with cascade } \\
\text { network structure) }\end{array}$ & Teeth detection \& classification & $\begin{array}{l}\text { Precision:- } 0.958, \text { Recall:- } 0.961 \\
\text { F-score :- } 0.959\end{array}$ \\
\hline $\begin{array}{l}\text { (Choi, Eun \& Kim, } \\
\text { 2018) }\end{array}$ & Conventional CNN & Caries detection & F1max:- 0.74 with FPs:- 0.88 \\
\hline (Lee et al., 2018b) & $\begin{array}{l}\text { GoogLeNet Inception v3 CNN } \\
\text { network }\end{array}$ & Caries and Non-caries & $\begin{array}{l}\text { Premolar Accuracy (premolar):- 0.89, } \\
\text { Accuracy(molar):- } 0.88 \text {, and Accuracy:- } \\
\text { 0.82, AUC (premolar):- 0.917, AUC } \\
\text { (molar):- } 0.890, \text { and an AUC (Both } \\
\text { premolar and molar):- } 0.845\end{array}$ \\
\hline (Lee et al., 2018a) & CNN (VGG-19) & $\begin{array}{l}\text { Periodontally compromised } \\
\text { teeth (PCT) }\end{array}$ & $\begin{array}{l}\text { For premolars, the total diagnostic } \\
\text { Accuracy(premolars):- } 0.810 \\
\text { Accuracy(molars):- } 76.7 \%\end{array}$ \\
\hline $\begin{array}{l}\text { (Geetha, Aprameya } \\
\text { \& Hinduja, 2020) }\end{array}$ & $\begin{array}{l}\text { Back-propagation neural } \\
\text { network }\end{array}$ & Caries detection & $\begin{array}{l}\text { Accuracy:- } 0.971, \text { FPR:- } 0.028, \text { ROC :- } \\
0.987, \text { PRC :- } 0.987 \text { with Learning rate:- } \\
0.4, \text { momentum:- } 0.2\end{array}$ \\
\hline \multicolumn{4}{|c|}{ Imaging modality: Panoramic X-rays } \\
\hline (Oktay, 2017) & AlexNet & $\begin{array}{l}\text { Teeth detection and } \\
\text { classification }\end{array}$ & $\begin{array}{l}\text { Accuracy(tooth detection):- } 0.90 \\
\text { Classification Accuracy: } \\
\text { Molar :-0.9432, Premolar:- } 0.9174 \text {, Canine } \\
\text { \& Incissor:- } 0.9247\end{array}$ \\
\hline (Chu et al., 2018) & $\begin{array}{l}\text { Deep octuplet siamese } \\
\text { network (OSN) }\end{array}$ & Osteoporosis analysis & Accuracy:- 0.898 \\
\hline $\begin{array}{l}\text { (Wirtz, Mirashi \& } \\
\text { Wesarg, 2018) }\end{array}$ & $\begin{array}{l}\text { Coupled shape model + neural } \\
\text { network }\end{array}$ & Teeth detection & $\begin{array}{l}\text { Precision:- } 0.790, \text { Recall:- } 0.827 \\
\text { Dice coefficient:- } 0.744\end{array}$ \\
\hline (Jader et al., 2018) & Mask R-CNN model & Teeth detection & $\begin{array}{l}\text { Accuracy:- } 0.98, \text { F1-score:- } 0.88, \\
\text { precision:- } 0.94, \text { Recall:- } 0.84 \text {, and } \\
\text { Specificity:- } 0.99\end{array}$ \\
\hline (Lee et al., 2019) & Mask R-CNN model & $\begin{array}{l}\text { Teeth segmentation for } \\
\text { diagnosis and forensic } \\
\text { identification }\end{array}$ & $\begin{array}{l}\text { F1 score:- } 0.875 \text {, Precision:- } 0.858 \text {, } \\
\text { Recall:- } 0.893 \text {, Mean'IoU':- } 0.877\end{array}$ \\
\hline (Kim et al., 2019) & $\begin{array}{l}\text { DeNTNet (Deep neural transfer } \\
\text { Network) }\end{array}$ & Bone loss detection & $\begin{array}{l}\text { F1 score:- } 0.75 \\
\text { Accuracy:- } 0.69\end{array}$ \\
\hline (Tuzoff et al., 2019) & $\mathrm{R}-\mathrm{CNN}$ & Teeth detection and numbering & $\begin{array}{l}\text { Tooth detection (Precision:- } 0.9945 \\
\text { Sensitivity:- } 0.9941 \text { ) } \\
\text { Tooth Numbering (Specificity:- 0.9994, } \\
\text { Sensitivity }=0.9800 \text { ) }\end{array}$ \\
\hline (Fukuda et al., 2019) & $\begin{array}{l}\text { DetectNet with DIGITS version } \\
5.0\end{array}$ & $\begin{array}{l}\text { Vertical root } \\
\text { fracture }\end{array}$ & $\begin{array}{l}\text { Recall:- } 0.75 \text {, Precision:- } 0.93 \\
\text { F-measure:- } 0.83\end{array}$ \\
\hline (Murata et al., 2019) & AlexNet & Maxillary sinusitis & $\begin{array}{l}\text { Accuracy:- } 0.875 \text {, Sensitivity:- } 0.867 \text {, } \\
\text { Specificity:- } 0.883 \text {, and AUC:- } 0.875 \text {. }\end{array}$ \\
\hline (Kats et al., 2019) & ResNet-101 & Plaque detection & $\begin{array}{l}\text { Sensitivity:- } 0.75 \text {, Specificity:- } 0.80 \text {, } \\
\text { Accuracy:- } 0.83 \text {, AUC:- } 0.5\end{array}$ \\
\hline $\begin{array}{l}\text { (Singh \& Sehgal, } \\
2020)\end{array}$ & 6 - Layer DCNN & $\begin{array}{l}\text { Classification of molar, } \\
\text { premolar, canine and incisor }\end{array}$ & $\begin{array}{l}\text { Accuracy (augmented database):- } 0.95 \text {, } \\
\text { Accuracy (original database):- } 0.92\end{array}$ \\
\hline $\begin{array}{l}\text { (Muramatsu et al., } \\
\text { 2020) }\end{array}$ & CNN (Resnet 50) & $\begin{array}{l}\text { Teeth detection and } \\
\text { classification }\end{array}$ & $\begin{array}{l}\text { Tooth detection sensitivity:- } 0.964 \\
\text { Average classification accuracy (single } \\
\text { model):- } 0.872 \text {, (multisized models):- } \\
0.932\end{array}$ \\
\hline (Banar et al., 2020) & Conventional CNN & Teeth detection & $\begin{array}{l}\text { Dice score:- } 0.93 \text {, accuracy:- } 0.54 \text {, a } \\
\text { MAE:- } 0.69 \text {, and a linear weighted } \\
\text { Cohen's kappa coefficient:- } 0.79 .\end{array}$ \\
\hline \multicolumn{4}{|c|}{ Imaging modality: Bitewing $\mathrm{X}$-rays } \\
\hline $\begin{array}{l}\text { (Srivastava et al., } \\
\text { 2017) }\end{array}$ & $\begin{array}{l}\text { Fully convolutional neural } \\
\text { network FCNN }\end{array}$ & Detection of dental caries & $\begin{array}{l}\text { Recall:- } 80.5 \text {, Precision:- } 61.5 \text {, } \\
\text { F-score:- } 70.0\end{array}$ \\
\hline \multicolumn{4}{|c|}{$\begin{array}{l}\text { Imaging modality: CT \& CBCT } \\
\end{array}$} \\
\hline (Miki et al., 2017a) & AlexNet architecture & $\begin{array}{l}\text { 7-Tooth-type classification } \\
\text { (canine, molar, premolar, etc.) }\end{array}$ & Accuracy:- 0.91 \\
\hline (Miki et al., 2017b) & AlexNet & $\begin{array}{l}\text { Teeth detection and } \\
\text { classification }\end{array}$ & $\begin{array}{l}\text { Detection accuracy:- } 0.774, \\
\text { Classification accuracy:- } 0.771\end{array}$ \\
\hline $\begin{array}{l}\text { (Hatvani et al., } \\
\text { 2018) }\end{array}$ & $\begin{array}{l}\text { Subpixel network + U-Net } \\
\text { architecture }\end{array}$ & Teeth resolution enhancement & $\begin{array}{l}\text { Mean of difference (area mm2):- } 0.0327 \\
\text { Mean of difference(micrometer):- } 114.26 \\
\text { Dice coefficient:- } 0.9101\end{array}$ \\
\hline
\end{tabular}




\begin{tabular}{|c|c|c|c|}
\hline $\begin{array}{l}\text { (Torosdagli et al., } \\
\text { 2018) }\end{array}$ & $\begin{array}{l}\text { CNN (a long short-term } \\
\text { memory (LSTM) network) }\end{array}$ & Anatomical Landmarking & DSC:- 0.9382 \\
\hline (Egger et al., 2018) & CNN (VGG16, FCN) & Mandible detection & $\begin{array}{l}\text { Accuracy:- } 0.9877 \text {, Dice coefficient:- } \\
0.8964 \text { and Standard deviation:- } 0.0169\end{array}$ \\
\hline $\begin{array}{l}\text { (Hiraiwa et al., } \\
\text { 2019) }\end{array}$ & AlexNet and GoogleNet & $\begin{array}{l}\text { Classification of root } \\
\text { morphology (Single or extra) }\end{array}$ & Diagnostic accuracy:- 0.869 \\
\hline \multicolumn{4}{|c|}{ Imaging modality: Hybrid dataset } \\
\hline (Wang et al., 2016) & $\begin{array}{l}\text { U-net architecture } \\
\text { (Ronneberger, Fischer \& Brox, } \\
\text { 2015) }\end{array}$ & $\begin{array}{l}\text { Landmark detection in } \\
\text { cephalometric radiographs and } \\
\text { Dental structure in bitewing } \\
\text { radiographs. }\end{array}$ & F-score $=>0.7$ \\
\hline $\begin{array}{l}\text { (Lee, Park \& Kim, } \\
\text { 2017) }\end{array}$ & LightNet and MatConvNet & Landmark detection & N.A \\
\hline $\begin{array}{l}\text { (Karimian et al., } \\
2018)\end{array}$ & Conventional CNN & Caries detection & $\begin{array}{l}\text { Sensitivity:- } 97.93 \sim 99.85 \% \\
\text { Specificity:- } 100 \%\end{array}$ \\
\hline \multicolumn{4}{|c|}{ Imaging modality: Color images/ Oral images } \\
\hline (Rana et al., 2017) & Conventional CNN & $\begin{array}{l}\text { Detection of inflamed and } \\
\text { healthy gingiva }\end{array}$ & $\begin{array}{l}\text { precision:- } 0.347 \text {, Recall: } 0.621, \text { AUC:- } \\
0.746\end{array}$ \\
\hline \multicolumn{4}{|c|}{ Image type not defined } \\
\hline $\begin{array}{l}\text { (Imangaliyev et al., } \\
\text { 2016) }\end{array}$ & Conventional CNN & Dental plaque & F1-score:- 0.75 \\
\hline
\end{tabular}

1 


\section{Table 6(on next page)}

Performance metrics used by various researchers for the dental image analysis 


\begin{tabular}{|c|c|c|}
\hline Metrics & Symbol & Author's \\
\hline True positive rate (sensitivity, recall) & $T P R$ & $\begin{array}{l}\text { (Hosntalab et al., 2010; Mortaheb, Rezaeian \& Soltanian- } \\
\text { Zadeh, 2013; Pushparaj et al., 2013; Ghaedi et al., 2014; Abdi, } \\
\text { Kasaei \& Mehdizadeh, 2015; Berdouses et al., 2015; Datta \& } \\
\text { Chaki, 2015b; Alsmadi, 2018; Datta, Chaki \& Modak, 2019, } \\
\text { 2020) }\end{array}$ \\
\hline True negative rate (specificity) & $T N R$ & $\begin{array}{l}\text { (Hosntalab et al., 2010; Mortaheb, Rezaeian \& Soltanian- } \\
\text { Zadeh, 2013; Ghaedi et al., 2014; Abdi, Kasaei \& } \\
\text { Mehdizadeh, 2015; Berdouses et al., 2015; Datta \& Chaki, } \\
\text { 2015b; Alsmadi, 2018; Datta, Chaki \& Modak, 2019) }\end{array}$ \\
\hline Positive predictive value (precision) & $P P V$ & $\begin{array}{l}\text { (Hosntalab et al., 2010; Mortaheb, Rezaeian \& Soltanian- } \\
\text { Zadeh, 2013; Pushparaj et al., 2013; Berdouses et al., 2015; } \\
\text { Datta, Chaki \& Modak, 2020) }\end{array}$ \\
\hline Jaccard index & $J A C$ & (Ji, Ong \& Foong, 2014) \\
\hline Dice coefficient & $D S C$ & $\begin{array}{c}\text { (Ji, Ong \& Foong, 2014; Abdi, Kasaei \& Mehdizadeh, 2015; } \\
\text { Datta, Chaki \& Modak, 2019; Devi, Banumathi \& } \\
\text { Ulaganathan, 2019) }\end{array}$ \\
\hline F-Measure $(\mathrm{F} 1 \mathrm{Measure}=$ Dice $)$ & $F M S$ & (Berdouses et al., 2015; Datta, Chaki \& Modak, 2020) \\
\hline Accuracy & $A C C$ & $\begin{array}{l}\text { (Huang \& Hsu, 2008; Olsen et al., 2009; Banu et al., 2014; } \\
\text { Nuansanong, Kiattisin \& Leelasantitham, 2014; Ghaedi et al., } \\
\text { 2014; Lin et al., 2014; Datta \& Chaki, 2015a,b; Poonsri et al., } \\
\text { 2016; Rad et al., 2018; Osterloh \& Viriri, 2019; Datta, Chaki } \\
\text { \& Modak, 2019, 2020; Devi, Banumathi \& Ulaganathan, } \\
\text { 2019; Kumar, Bhadauria \& Singh, 2020) }\end{array}$ \\
\hline Mahalanobis distance & $M H D$ & (Pushparaj, Gurunathan \& Arumugam, 2013) \\
\hline Hausdorff distance & $H D$ & (Abdi, Kasaei \& Mehdizadeh, 2015) \\
\hline Distance vector & $D V$ & (Prajapati, Desai \& Modi, 2012) \\
\hline Similarity measure & $S M$ & $\begin{array}{c}\text { (Pushparaj, Gurunathan \& Arumugam, 2013; Alsmadi, 2018; } \\
\text { Singh \& Agarwal, 2018) }\end{array}$ \\
\hline The area under ROC curve & $A U C$ & (Nuansanong, Kiattisin \& Leelasantitham, 2014) \\
\hline Cohens kappa coefficient & KAP & (Berdouses et al., 2015) \\
\hline Mean absolute error & $M A E$ & $\begin{array}{c}\text { (Vijayakumari et al., 2012; Amer \& Aqel, 2015; Tuan et al., } \\
\text { 2018; Kumar, Bhadauria \& Singh, 2020) }\end{array}$ \\
\hline Mean square error & $M S E$ & $\begin{array}{c}\text { (Vijayakumari et al., 2012; Singh \& Agarwal, 2018; Tuan et } \\
\text { al., 2018) }\end{array}$ \\
\hline Error rate & $E R R$ & $\begin{array}{l}\text { (Zhou \& Abdel-Mottaleb, 2005; Nomir \& Abdel-Mottaleb, } \\
\text { 2008; Hosntalab et al., 2010; Harandi \& Pourghassem, 2011; } \\
\text { Lira et al., 2014; Datta \& Chaki, 2015b; Purnama et al., 2015; } \\
\text { Tuan et al., 2018; Banday \& Mir, 2019) }\end{array}$ \\
\hline Failure rate & $F R$ & (Said et al., 2006; Al-sherif, Guo \& Ammar, 2012) \\
\hline
\end{tabular}

1 


\section{Table 7 (on next page)}

Confusion matrix 


\begin{tabular}{|l|l|}
\hline $\begin{array}{l}\text { True positive rate (Recall/Sensitivity): It implies how the caries lesion is } \\
\text { accurately detected when it is present there. }\end{array}$ & Sensitivity is expressed as $\frac{T P}{T P+F N}$ \\
$\begin{array}{l}\text { True negative rate (Specificity): That is the amount of negative caries lesion } \\
\text { examination when there's no affected lesion. }\end{array}$ & Specificity is measured as $\frac{\mathrm{TN}}{\mathrm{TN}+\mathrm{FP}}$ \\
\hline $\begin{array}{l}\text { Dice Coefficient: This metric measures between two samples. } \\
\text { Accuracy can be defined as the percentage of correctly classified instances. }\end{array}$ & $\begin{array}{l}\text { It is defined as } \frac{(2|\mathrm{~A} \cap \mathrm{B}|)}{(|\mathrm{A}|+|\mathrm{B}|)} \text {, where }|\mathrm{A}| \text { and }|\mathrm{B}| \text { are the } \\
\text { number of elements in the sample. }\end{array}$ \\
\hline $\begin{array}{l}\text { Precision: } \text { It explains the pureness of our positive detections efficiently } \\
\text { compared to the ground truth. }\end{array}$ & It is calculated as $\frac{\mathrm{TP}+\mathrm{TN}}{\mathrm{TP}+\mathrm{TN}+\mathrm{FN}+\mathrm{FP} * 100 .}$ \\
\hline $\begin{array}{l}\text { F-Score: } \text { The F-score is a process of combining the model's precision and recall } \\
\text { and the harmonic mean of the model's precision and recall. }\end{array}$ & It is expressed as $2 \times \frac{\text { Precision } \times \text { Recall }}{\text { Precision }+ \text { Recall }}$ \\
\hline
\end{tabular}

1 


\section{Table 8 (on next page)}

Dental X-ray image dataset description used for deep learning methods 


\begin{tabular}{|c|c|}
\hline Authors \& Year & Dataset Description \\
\hline (Eun \& Kim, 2016) & $\begin{array}{l}\text { Periapical X-rays: } 500 \text { periapical images used for training where each Image is containing five teeth and } \\
100 \text { images used for testing with corresponding ground truth. }\end{array}$ \\
\hline (Wang et al., 2016) & $\begin{array}{l}\text { Total number of patients: } 400 \text { ( } 100 \text { additional patients) } \\
\text { Cephalometric radiographs: } 400 \text { images .tiff format dimension of } 1935 \times 2400 \text { pixels, } 120 \text { bitewing } \\
\text { radiographs (new) (Age group } 6 \text { to } 60 \text { yrs) } \\
\text { Software used: Soredex CRANEXr Excel Ceph machine (Tuusula, Finland) and Soredex SorCom } \\
\text { software (3.1.5, version 2.0) }\end{array}$ \\
\hline $\begin{array}{l}\text { (Prajapati, Nagaraj \& Mitra, } \\
\text { 2017) }\end{array}$ & $\begin{array}{l}\text { Periapical RadioVisio Graphy (RVG) X-ray: } 251 \text { images (labeled dataset) where } 180 \text { used for training, } 26 \\
\text { images for testing \& } 45 \text { images validation. }\end{array}$ \\
\hline (Rana et al., 2017) & Color images: Training and validation data consist of 258 images \& 147 images. \\
\hline (Lee, Park \& Kim, 2017) & $\begin{array}{l}300 \text { Dental X-ray images with resolution } 1935 \times 2400 \text { pixels and } 150 \text { images used for training, and } 150 \\
\text { images used for testing. }\end{array}$ \\
\hline (Srivastava et al., 2017) & Bitewing images: More than 3000 images \\
\hline (Miki et al., 2017a) & $\begin{array}{l}\text { CBCT dataset taken from Asahi University Hospital, Gifu, Japan. } \\
2 \text { dental units: Veraviewepocs 3D (J.Morita Mfg, Corp., Kyoto, Japan) and Alphard VEGA (Asahi } \\
\text { Roentgen Ind. Co., Ltd., Kyoto, Japan }\end{array}$ \\
\hline (Miki et al., 2017b) & CT data: 52 images, Training group: 42 images, testing group: 10 images \\
\hline (Oktay, 2017) & $\begin{array}{l}\text { Panoramic Images: Dataset taken from 3-different X-ray machines have image dimensions } 2871 \times 1577 \text {, } \\
1435 \times 791 \text {, or } 2612 \times 1244 \text { pixels. Testing and validation are done using images of } 100 \text { different people. }\end{array}$ \\
\hline (Yang et al., 2018) & A small dataset of 196 periapical images used, and also augmentation is performed. \\
\hline (Zhang et al., 2018) & $\begin{array}{l}\text { Periapical Images: Initially for training, } 800 \text { images and } 200 \text { used for testing. } \\
\text { and data is annotated with the help of bounding box labels in } 32 \text { teeth position. }\end{array}$ \\
\hline (Wirtz, Mirashi \& Wesarg, 2018) & $\begin{array}{l}\text { Panoramic X-rays: } 14 \text { test images used. } \\
\text { Image augmentation is used to increase training images up to } 4000 .\end{array}$ \\
\hline (Choi, Eun \& Kim, 2018) & Periapical X-rays: 475 images dimension of $300 \times 413$ from $688 \times 944$ or $1200 \times 1650$ \\
\hline (Jader et al., 2018) & $\begin{array}{l}\text { Panoramic X-ray images: } \\
193 \text { images used for training containing } 6987 \text { teeth and } 83 \text { images for validation containing } 3040 .\end{array}$ \\
\hline (Lee et al., 2018b) & $\begin{array}{l}\text { Periapical Images: } 3000 \text { images .jpeg format dimension resized to } 299 \times 299 \text { pixels The training and } \\
\text { validation dataset was } 2400 \text { and a test dataset of } 600 \text {. The training and validation dataset consisted of } \\
1200 \text { dental caries and } 1200 \text { non-dental caries, and the test dataset consisted of } 300 \text { dental caries and } 300 \\
\text { non-dental caries. Augmentation is done up to } 10 \text { times for training. }\end{array}$ \\
\hline (Hatvani et al., 2018) & Micro CT images: a training set consists of 5680 slices and a test set of 1824 slices was used. \\
\hline (Torosdagli et al., 2018) & $\begin{array}{l}\text { CBCT dataset of } 50 \text { patients and qualitative visual inspection were done for } 250 \text { patients with high } \\
\text { variability. }\end{array}$ \\
\hline (Karimian et al., 2018) & $\begin{array}{l}\text { Training is performed using different batches containing ten optical coherence tomography (OCT) } \\
\text { images per batch. }\end{array}$ \\
\hline (Lee et al., 2018a) & $\begin{array}{l}\text { Periapical X-ray images resized to } 224 \times 224 \text { pixels (from the original } 1,440 \times 1,920 \text { pixels) in } \text {.png format: } \\
\text { For training }(n=1,044) \text {, validation }(n=348) \text {, and test }(n=348) \text { datasets. }\end{array}$ \\
\hline (Egger et al., 2018) & $\begin{array}{l}\text { CT dataset containing } 45 \text { images as DICOM files with dimension } 512 \times 512 \text { from a department of } \\
\text { craniomaxillofacial surgery in Austria. } 1^{\text {ts }} \text { Image set containing } 1680 \text { slices, } 2^{\text {nd }} \text { one with induced noise } \\
\text { images } 6720 \text { slices, } 3^{\text {rd }} \text { after transformation } 13440 \text { slices, and } 4^{\text {th }} \text { covered augmentation } 18480 \text { slices }\end{array}$ \\
\hline (Chu et al., 2018) & Panoramic X-ray: 108 images. \\
\hline (Hiraiwa et al., 2019) & CBCT images and panoramic radiographs used for 760 mandibular first molars (400 patients) \\
\hline (Lee et al., 2019) & $\begin{array}{l}\text { Panoramic X-rays: Dimensions of } 2988 \times 1369 \text { pixels. } \\
\text { Total } 846 \text { annotated tooth images. } \\
\text { Training group: } 30 \text { radiographs, Validation \& testing: } 20 \text { images. } \\
\text { Augmentation technique used to reduce overfitting ( obtained } 1024 \text { training samples from } 846 \text { original } \\
\text { data points ) }\end{array}$ \\
\hline (Kim et al., 2019) & $\begin{array}{l}\text { Panoramic Images:12,179 images (annotated by experts) } \\
\text { Trained, validated, and tested using } 11,189,190 \text {, and } 800 .\end{array}$ \\
\hline (Tuzoff et al., 2019) & $\begin{array}{l}\text { Panoramic radiographs: } 1352 \text { images } \\
\text { Training group: } 1352 \text { images, Testing group: } 222 \text { images }\end{array}$ \\
\hline (Murata et al., 2019) & $\begin{array}{l}\text { Panoramic X-rays: Total patients: } 100 \text { ( } 50 \text { men and } 50 \text { women), Training data for } 400 \text { healthy and } 400 \\
\text { inflamed maxillary sinuses and data augmentation used to make } 6000 \text { samples }\end{array}$ \\
\hline (Kats et al., 2019) & Panoramic X-ray:65 images and augmentation performed. \\
\hline (Fukuda et al., 2019) & $\begin{array}{l}\text { Panoramic X-ray: } 300 \text { images with } 900 \times 900 \text { pixels. } \\
\text { Training set: } 240 \text { images, Testing set: } 60 \text { images }\end{array}$ \\
\hline (Singh \& Sehgal, 2020) & $\begin{array}{l}\text { Panoramic X-rays: Total } 400 \text { images. Training group: } 240 \text { images, Testing group: } 160 \text { images. Also, } \\
\text { augmentation is done by using transformation. }\end{array}$ \\
\hline (Muramatsu et al., 2020) & Panoramic X-rays: 100 images dimension of $3000 \times 1500$ pixels used for testing and training both. \\
\hline $\begin{array}{l}\text { (Geetha, Aprameya \& Hinduja, } \\
\text { 2020) }\end{array}$ & $\begin{array}{l}\text { Periapical X-rays: } 105 \text { images saved as in } . \text { bmp format dimension resized to } 256 \times 256 \text {, where caries } \\
\text { identified } 49 \text { images } \\
\text { Training, validation, and testing consists of } 49 \text { caries and } 56 \text { sound dental X-ray images. }\end{array}$ \\
\hline (Banar et al., 2020) & Panoramic(OPGs) image dataset of 400 images used. \\
\hline
\end{tabular}

